\title{
Ser, esencia y atributos divinos: el conocimiento de Dios en la metafísica tomasiana según la interpretación de Jean-Luc Marion
}

\author{
Fernanda Ocampo \\ CONICET/UBA/UNR
}

Resumen: Para Jean-Luc Marion, el pensamiento tomasiano no se deja encerrar en los parámetros de la metafísica onto-teo-lógica, tal como es definida por Martin Heidegger. Esto implica, respecto de Dios, que, si ya no ha de ser llamado "ente supremo", pues para Tomás Dios se revela como el "Ser mismo", carente de esencia, éste se caracteriza por su absoluta incognoscibilidad. Para sustentar esta interpretación, Marion recurre a una serie de tesis que entiende se desprenden de la consideración de algunos textos del Aquinate. En el presente trabajo se analizan algunas de estas tesis en función de dichos textos (y de algunos nuevos), y se propone una lectura alternativa a la del autor. Se intenta mostrar particularmente que, a los ojos de Tomás, sí es posible atribuir la noción de "esencia" a Dios, y también, alcanzar un conocimiento verdadero, aunque imperfecto y limitado de la realidad divina, a partir de la predicación positiva de ciertas perfecciones absolutas que se encuentran en las creaturas.

Palabras clave: onto-teo-logía; metafísica del ser; conocimiento de Dios; esencia divina; atributos divinos

\begin{abstract}
Being, Essence and Divine Attributes: The Knowledge of God in Thomasian Metaphysics according to the Interpretation of Jean-Luc Marion". For Jean-Luc Marion, the thought of Aquinas is not to be understood under the parameters of the onto-theo-logical metaphysics defined by Martin Heidegger. This implies with respect to God that, if he is no longer to be called "supreme being" (ens) since for Aquinas God is revealed as the "Act of Being" (esse lacking in essence), then he is characterized by his absolute unknowability. To support this interpretation, Marion turns to a series of theses that he considers are derived from the reading of some of Aquinas' texts. In this article, some of these theses are analyzed in relation to those texts (and to some new ones), and an alternative reading to the one of the author is proposed. It is particularly stressed that, in the eyes of Thomas Aquinas, it is possible to attribute the notion of "essence" to God, and to reach a true but imperfect and limited knowledge of the divine reality based on the positive predication of certain absolute perfections that are found in creatures.
\end{abstract}

Keywords: onto-theo-logy; metaphysics of the Act of Being; knowledge of God; divine essence; divine attributes 


\section{Introducción}

En la segunda edición de su libro Dieu sans l'être', Jean-Luc Marion dedica un último capítulo a la consideración de la filosofia de Tomás de Aquino en relación con el concepto de "onto-teo-logía" forjado por Martin Heidegger para definir la esencia invariable de la metafisica occidental. En dicho capítulo, el autor se propone determinar si efectivamente la doctrina del Aquinate puede reducirse a fin de cuentas a una onto-teo-logía (perdiendo así todo privilegio por sobre otras metafísicas, de similares características). Para esto, Marion procura primero definir exactamente los rasgos de la onto-teo-logía según Heidegger, y luego establecer si, y en qué medida, todas o algunas de las tesis de Tomás de Aquino coinciden con dicha descripción. Con respecto a esto, nuestro trabajo indagará en términos generales la lectura que Marion realiza acerca de este entrecruzamiento y buscará determinar, en la medida de nuestras posibilidades y dentro de ciertos límites, si las afirmaciones que el autor realiza acerca de la filosofia tomasiana resultan del todo ajustadas al pensamiento del Aquinate, en función de sus textos más relevantes.

En este sentido, dado que nuestro principal foco de interés radica en la cuestión de saber si, para Tomás de Aquino, es posible alcanzar algún tipo de conocimiento filosófico-natural de la realidad divina, procederemos del siguiente modo: en primer lugar, reseñaremos las tesis centrales de Marion respecto de la doctrina de Tomás en relación con la "onto-teo-logía", para brindar un marco teórico sólido para nuestros análisis; en segundo lugar, examinaremos cuidadosamente algunas de estas tesis a la luz de los textos más significativos del Aquinate, considerando de manera particular aquellos puntos que revisten especial importancia para la determinación de la posición tomasiana en torno a la posibilidad de un conocimiento metafisico de Dios. Concretamente, examinaremos primero aquellos pasajes en los que Tomás adjudica a Dios ciertos atributos (perfecciones absolutas) que encontramos en las creaturas y, luego, aquellos en los que aborda la noción de essentia en cuanto referida a la realidad

\footnotetext{
1 En el presente trabajo haremos uso de la edición de 2002 de Dieu sans l'être de Jean-Luc Marion. En esta nueva edición (revisada y aumentada) y en las siguientes ediciones (2010, 2013), Marion presenta el capítulo acerca de Tomás y la onto-teo-logía (VIII) como una retractatio de su antigua posición en torno a este tema, adoptada en 1982. Las traducciones de este texto son nuestras.
} 
divina. Nuestra hipótesis es que, al contrario de lo que opina Marion, los textos de Tomás sí permiten hablar de la posibilidad de un cierto conocimiento natural verdadero, aunque imperfecto y limitado, de la realidad divina. Finalmente, expondremos nuestras conclusiones.

\section{Las tesis centrales de Marion}

Afirma Marion que, con su concepto de onto-teo-logia, Heidegger habría puesto en marcha "una nueva definición de la esencia de la metafísica" 2 . Por un lado, esta estaría caracterizada por una necesaria incapacidad de pensar la diferencia entre el ente (ens) y el ser (esse) en cuanto tal, no accediendo al "ser" sino solo en tanto que "ente" y, por el otro, por una lectura de Dios como "ente supremo"3. En concreto, los rasgos esenciales de la onto-teo-logía se derivan, según Marion, de la exigencia de una triple "fundación": esto es, el ser, en la medida en que difiere de todo ente (y no es "nada" del ente), puede "fundar" todo ente y todos los entes, incluido a "Dios"4. Recíprocamente, el primer ente declarado en toda metafísica no solo funda los otros entes a título de causa primera, sino que funda también el ser del ente ${ }^{5}$. Sin embargo, para esto, el ente supremo, que ejerce una fundación sobre todos los otros entes y sobre el ser, debe también asumir su propia fundación definiéndose como causa suí. De todo esto, resultan las características esenciales que definen a la onto-teología según Marion: que "el dios" debe inscribirse explícitamente en el campo metafisico, esto es, dejarse determinar por una de las determinaciones históricas

2 Ibid., p. 280.

3 "En effet, pour autant que le concept d'onto-théo-logie définit strictement toute métaphysique et que chaque métaphysique se caractérise par sa nécessaire impuissance à penser comme telle la différence entre l'étant et l'être, il faudrait en inférer que, par sa constitution onto-théo-logique même, aucune métaphysique n'accède pas à l'être en tant que tel, mais seulement à l'être en tant qu'étant" (ibid.). Y más abajo: "Bien plus, puisque l'onto-théo-logie ne pense par définition jamais l'être qu'en rapport avec l'étant, et se confondant avec lui, cette hypothèse interdirait à la pensée de saint Thomas, si elle se l'appropriait, de prétendre avoir atteint l'acte d'être, l'actus essendi comme la définition propre de Dieu: car s'il pouvait éventuellement s'agir de Dieu, ce ne serait déjà ou encore que comme étant suprême, mais sûrement pas de l'être" (ibid., p. 281).

4 “...(i) L'être, en tant qu'il diffère décidément de tout étant, se déclare comme rien d'étant... en tant qu'un tel néant d'étant, il peut fonder tout étant et tous les étants, y compris 'Dieu'"(ibid., p. 283).

"Réciproquement, l'étant, en particulier l'étant premier déclaré dans chaque métaphysique, non seulement fonde les autres étants à titre de cause première... mais fonde aussi l'être de l'étant en tant qu'il en accomplit à la perfection et jusque dans l'existence les caractéristiques formelles d'étantité" (ibid., p. 283).

6 “...[1'étant par excellence] doit donc retourner sur soi la fondation efficiente et causale qu'il exerce sur les autres étants; il se définit, quelque nom qu'il porte, par sa fonction principielle de causa sui" (ibid., p. 286). 
del ser en tanto que "ente"; que "el dios" debe asegurar una fundación causal de todos los entes de los que da razón; y que debe asumir su función de causa sui como ente supremamente fundador en tanto supremamente fundado por sí mismo ${ }^{7}$.

Habiendo entonces establecido estas características, Marion pasa a determinar si el pensamiento de Tomás de Aquino se corresponde o no con los criterios de una metafísica onto-teo-lógica. Así pues, en relación con el primer punto (si Dios está incluido en la metafísica, de manera tal de constituir un "dios" de la metafisica ${ }^{8}$ ), Marion responde aludiendo a la distinción tomasiana entre la theologia sive scientia divina, que es parte de la metaphysica como disciplina estrictamente filosófica y natural, y la teología en el sentido de sacra doctrina. Pues bien, solo la teología entendida en este último sentido puede pretender conocer las cosas divinas en ellas mismas ${ }^{9}$. Al contrario, la teología que es parte de la metaphysica solo puede alcanzar las cosas divinas por sus efectos, los cuales constituyen el único tema legítimo de la metaphysica, a saber, el ente en tanto que ente ${ }^{10}$. De hecho, en la medida en que solo los efectos, y no las cosas divinas mismas, se dicen según la "entidad" y como "entes", las cosas divinas no se inscriben directamente en la teología de la metaphysica, sino que esta las considera apenas indirectamente a título de "principio" de estos efectos"1.

De esta manera, en la medida en que Dios permanece en la posición de "principio" del objeto de la metafisica, no pertenece "en cuanto tal" ni a la metaphysica, ni a su teología, ni al ens commune, ni al ens in quantum ens ${ }^{12}$. En esto, sostiene Marion, Tomás se diferencia de otros autores (como Egidio Romano, Juan Duns Escoto, y Francisco Suárez), quienes, al hacer de Dios un

7 “...(i) 'Le dieu' doit s'inscrire explicitement dans le champ métaphysique, c'est-à-dire, c'est laisser déterminer à partir d'une des déterminations historiques de l'être en tant qu'étant, éventuellement, à partir du concept d'étant; (ii) il doit y assurer une fondation causale (Begründung) de tous les étants communs dont il rend raison; (iii) il doit assumer toujours la fonction et éventuellement le nom de causa sui, c'est-à-dire, de l'étant suprêmement fondateur parce que suprêmement fondé par lui-même" (ibid., p. 287).

8 "Il faut donc d'abord demander si Thomas d'Aquin inclut Dieu dans la métaphysique, au sens où sa fonction de fondation lui donnerait rang d'un 'dieu' de la métaphysique ?” (ibid., p. 288).

$158 \quad 9$ "...seule la théologie au sens de la sacra doctrina peut prétendre connaître les choses divines en elles-mêmes" (ibid., p. 289).

10 “...Quant à la théologie ‘... quam Philosophi prosequuntur, qua alio nomine Metaphysica dicitur', elle ne peut atteindre les choses divines que par leurs effets... en tant que ceux-ci seuls relèvent du seul sujet légitime de la metaphysica, l'ens in quantum ens" (ibid., p. 289).

11 “...les choses divines ne s’inscrivent pas directement dans la théologie de la métaphysique... mais n'y interviennent qu'indirectement, à titre de principe des choses (substrat), mais non comme des telles choses" (ibid., p. 290).

12 "Ainsi, pour Thomas d'Aquin, Dieu, en tant que tel, n'appartient ni à la métaphysique, ni à sa théologie, ni à l'ens commune, ni à l'ens in quantum ens" (ibid., p. 291). 
"ente", radicalizan un concepto "unívoco" de "ente" para lo creado e increado: de esta manera, se incluye a Dios en el ens commune, (con la sola prerrogativa de su infinitud) y en el objeto de la metafísica ${ }^{13}$. El autor destaca, frente a estos pensadores, la originalidad del pensamiento tomasiano, estableciendo así su sustracción al primer requisito de la onto-teo-logía, a saber, que Dios "caiga bajo la jurisdicción" del ser en tanto que "ente".

Ahora bien, para descartar toda posibilidad de duda en relación con esta última tesis, finalmente Marion considera ineludible analizar aquel concepto por el cual podría de todas maneras afirmarse que en el pensamiento tomasiano sería viable no solo la inscripción de Dios en la metafísica, sino también la posibilidad de que una misma noción se diga tanto de Dios ("ente" supremo) como del ente en tanto que ente (se refiere aquí, el autor, a la noción de "analogía"). Efectivamente, si la univocidad del ente ha sido descartada (en la medida en que constituiría una "traición" al auténtico pensamiento de Tomás), queda aún por explicar cómo la "analogía" no cumple, de alguna manera, con la misma función en la filosofía tomasiana. A este respecto, el autor señala que si la metafísica tiene como objeto el "ente" (definido por su primacía desde un punto de vista noético) o el esse commune, para Tomás, el "ente" no puede de ninguna manera aplicarse a Dios, pues el esse divino se encuentra por definición fuera del entendimiento humano y no puede confundirse con el ser común ${ }^{14}$.

En efecto, afirma, Marion, el "ente común no puede introducir nada de común -y en especial su inteligibilidad- entre el ente en tanto que ente y Dios"15, pues el esse divino aparece, justamente, como lo "desconocido"16. De esta manera, si el esse de la metafísica, válido para los entes creados, obtiene su primacía a partir de su inteligibilidad, y el esse divino se sustrae, justamente, a dicha inteligibilidad en su representación por el entendimiento, entonces, el ser de Dios queda "fuera" del dominio del ente tal como la metafisica pretende

\footnotetext{
13 “...il s'oppose par avance à ses successeurs, qui, très rapidement, inverseront ce choix afin de réintégrer Dieu dans la métaphysique et son objet" (ibid., p. 291); "C'est donc bien l'objet de la métaphysique-l'étant radicalisé en un concept d'étant univoque pour le créé et l'incréé-qui englobe Dieu à la fois dans l'ens commune (avec la seule correction de l'infinité) et dans la métaphysique" (ibid., p. 292).

14 “...Ainsi, et surtout, cette conception de l'ens ne concerne précisément pas Dieu... parce zque l'esse divin ne se confond pas avec l'esse commun... . Dieu est par définition hors de l'entendement seul; donc il ne peut se confondre avec l'esse commune" (ibid., p. 295).

15 “...L'étant commun ne peut, suivant Thomas d'Aquin, rien introduire de commun -et surtout pas son intelligibilité- entre l'étant en tant qu'étant et Dieu" (ibid., p. 297).

16 “...et c'est bien pourquoi l'esse propre à Dieu seul, en s'arrachant de la métaphysique, se libère aussi de son type d'intelligibilité, jusqu'à apparaître, à son égard, rien de moins qu'inconnu" (ibid., p. 296).
} 
delimitarlo ${ }^{17}$. A este respecto, para el Aquinate, la analogía del ser tendría como función ahondar el abismo que separa estas dos acepciones del esse: la del ser común y la del ser divino ${ }^{18}$. En este sentido, según el decir de Marion, la "distinción real" en el seno del ente finito entre el esse y la essentia opera especialmente como marca distintiva de la creatura, por lo que esta queda separada abismalmente de Dios, cuya esencia no se distingue de su actus essendi ${ }^{19}$. Es este modo de ser propio de Dios (y exclusivo de Él), lo que lo distancia justamente de todo ente y de la entidad en general. En conclusión, si Dios debiera "ser", no sería jamás como formando parte del objeto de la metafísica y, sobre todo, según un concepto unívoco del ente ${ }^{20}$.

Habiendo entonces descartado que la primera característica de la ontoteo-logía corresponda al pensamiento de Tomás, Marion se aboca al análisis de la segunda exigencia: esto es, la fundación o causalidad eficiente de los entes por parte de Dios. Según este criterio, la entrada en la entidad de los entes creados, quedaría asegurada por la causalidad eficiente de Dios, la cual permitiría a su vez, conocer al Creador en tanto causa y bajo la razón de la causalidad ${ }^{21}$. Así, los nombres que se dicen de Dios ("bueno", "bello", "verdadero") no valen sino como atribuidos a partir de los efectos de los que proceden ${ }^{22}$. Sin embargo, sostiene el autor, Tomás de Aquino reinterpreta la relación causal entre lo creado y lo increado de acuerdo a los requerimientos de la analogía, es decir, exigiendo respetar la distancia de "desconocimiento" 23 en la medida en que los entes causados se encuentran infinitamente excedidos por la causa que los

\footnotetext{
17 “...si d'une part, l'esse de la métaphysique, valable pour les étants créés, tire sa primauté de son intelligibilité, si d'autre part l'esse divin se soustrait au contraire à celui de la métaphysique, alors il doit se dégager aussi de son intelligibilité” (ibid., p. 297). En otras palabras: “...Thomas d'Aquin ne récuse pas seulement par avance tout conceptus univocus entis, il révoque surtout le nœud central de toute onto-théo-logie -que les opérateurs théologique et ontologique puissent s'y fonder réciproquement, donc à l'intérieur d'une détermination commune" (ibid., p. 297).

18 “...L'analogie de l'être... n'a jamais d'autre fonction, pour lui, que de creuser le gouffre qui sépare ces deux acceptions de l'esse" (ibid., p. 297).

19 “...La différence entre l'être et l'essence... telle qu'elle traverse pour ainsi dire horizontalement tous les étants créés, non seulement s'annule devant Dieu, mais devient l'instrument d'une toute autre différence, pour ainsi dire verticale, entre la différence ousio-ontique prise globalement, d'une part, et l'indifférence ousio-ontique de Dieu, d'autre part" (ibid., p. 298).

20 “...si d'aventure Dieu devait être, ce ne serait jamais comme faisant partie de l'objet (ou du sujet) de la metaphysica, ni surtout selon un concept univoque d'étant" (ibid., p. 300).

21 “...Car non seulement la causalité efficiente assure l'entrée dans l'étantité des étants créés, (de Dieu au monde), mais elle permet, en retour (du monde à Dieu) de connaître le créateur en tant que cause et sous le rapport de la causalité" (ibid., p. 301).

22 “...les noms attribués à Dieu ne valent évidemment comme tels que des effets dont ils viennent" (ibid., p. 302).

23 “...Thomas d'Aquin... réinterprète la relation causale entre le créé et l'incréé conformément aux exigences de l'analogie, c'est-à-dire, en lui imposant de respecter l'écart d'inconnaissance, donc
} 
funda, y así permanecen respecto a ella definitivamente "inadecuados" 24 . La fundación resulta, entonces, unilateral y no recíproca, dotada de una asimetría esencial, no recibiendo Dios (en cuanto esse) ninguna contra-fundación que pudiera dotarlo de inteligibilidad ${ }^{25}$. La trascendencia de Dios queda de esta forma garantizada, no solo respecto de los entes, sino también respecto del "ser" del ente o esse commune.

En efecto, situando al Aquinate en la linea del Liber de causis, obra en la que se sostiene que el ser (esse) es la primera de las cosas creadas ("prima rerum creatarum est esse"), Marion argumenta que el ser de Dios excede el "ser" a título de la primera creatura. En sus palabras: "lo más esencial, lo más interno, lo más profundo dentro del ente creado es ciertamente el ser, que el ente recibe del actus essendi de Dios: pero este ser, le adviene también y de antemano como un esse creado. El ente creado recibe sin duda su esse del esse divino, pero, precisamente, porque lo recibe a título de creado, lo recibe como creado" 26 . En consecuencia, en la interpretación de Marion, queda claro que una causalidad tal no contradice la "distancia" entre Dios y la creatura, sino que más bien la realiza: la "existencia" de la causa puede ser inferida a partir de los efectos; sin embargo, su "esencia" nos es absolutamente desconocida ${ }^{27}$. Dios, que ahora se dice más ajustadamente ser (esse) y no ente (ens), se encuentra en el fundamento del esse commune, sobrepasándolo de tal manera que no admite ni requiere de ninguna fundación de su parte. La conclusión se impone con toda la fuerza: "el esse commune nada tiene de común con el esse divino"28.

Finalmente, Marion se propone determinar la pertinencia en la filosofia tomasiana del tercer criterio de la onto-teo-logía, a saber, que Dios asume la función de causa sui como de ente supremamente fundado por sí mismo. A este respecto, Marion denuncia fácilmente la contradicción lógica que un

de ne pas se résumer en une fondation, dont les termes pourraient se fonder réciproquement" (ibid., p. 303).

24 “...les causés, s'ils se fondent réellement dans la cause, se trouvent en retour infiniment excédés par elle... bien que totalement déterminés par elle, ou par cela même, ils lui restent définitivement inadéquats" (ibid., p. 304).

25 “...la fondation reste unilatérale, non réciproque: elle va au causé par la cause, mais jamais à la cause par le causé” (ibid., p. 304).

26 “...Le plus essentiel, le plus interne, le plus profond dans l'étant créé reste certes l'esse, qu'il reçoit de l'actus essendi de Dieu... mais cet esse lui advient aussi et déjà comme un esse créé. L'étant créé reçoit sans doute son esse de l'esse divin, mais, précisément parce qu'il le reçoit à titre de créé, il le reçoit comme créé" (ibid., p. 308).

27 “...une telle causalité ne contredit pas la distance, mais l'accomplit... la cause, même si son existence peut s'inférer des effets en autant de viae, n'en garde pas moins une essence absolument inconnue" (ibid., p. 309).

28 “...l'esse commune n'a rien de commun avec un tel esse divin” (ibid., p. 310). 
enunciado como tal implica, y que claramente Tomás rechaza: de ninguna manera puede Dios ser definido como causa sui, pues ninguna cosa puede causarse a sí misma, ya que debería entonces no solo diferir de sí misma, sino, sobre todo, ser anterior a sí misma ${ }^{29}$. Sin embargo, para Marion, el punto central se encuentra en el hecho de que, para que Dios pueda ser la causa primera que exige distancia, debe sustraerse a toda causa, lo que quebranta la regla "metafísica" universal de que todo existente posee una causa ${ }^{30}$. De esta manera, queda Dios exceptuado una vez más del ser común y de la metafísica. Así, la tercera y última característica de la onto-teo-logía queda suprimida de la filosofia tomasiana y Marion concluye que el pensamiento del Aquinate no se deja encerrar en la constitución onto-teo-lógica de la metafísica en el sentido en que Heidegger la postula.

Ahora bien, no es aquí donde culmina la reflexión de Marion, sino que ésta se extiende a la consideración de una posible objeción, que abordaremos en la medida en que, creemos, termina de dar cuenta del pensamiento profundo y original del autor. En palabras del autor: "la constitución onto-teo-lógica exige que la cuestión de Dios se despliegue en el horizonte del ser... Pues bien, Tomás de Aquino, parece ser, si no el primero, al menos el que más emblemáticamente ha establecido que el conocimiento de Dios, incluso el teológico, puede y debe llevarse a cabo en el horizonte privilegiado del ser"31. Bajo esta perspectiva, asumiendo el nombre de esse o actus essendi, el Dios tomasiano parecería manifestarse no solamente en el ser, sino como ser, convirtiéndose así Tomás en uno de los principales y más radicales exponentes de la onto-teología. ¿Cómo resuelve Marion esta objeción?

Pues bien, la respuesta reza así: "Tomás podría exceptuar a Dios del ser, tomado no solamente en el sentido de la metaphysica, sino también en el sentido de la onto-teo-logía, en la medida en que despliega un esse radicalmente diferente, tanto del ens y del conceptus univocus entis, como del ser entrevisto por

$162 \quad 29$ “...Dieu ne peut se définir une causa sui, parce que, aucune chose ne peut se causer ellemême, puisqu'elle devrait alors non seulement différer de soi, mais surtout se précéder ellemême" (ibid., p. 311).

30 "...pour que Dieu puisse exercer de plein droit la cause qu'exige la distance, il devrait lui-même se soustraire à la causalité... l'esse divin n'admet aucune cause, précisément parce qu'il exerce la causalité envers les seuls entia" (ibid., p. 312).

31 “...La constitution onto-théo-logique demande... que la question de Dieu puisse se déployer dans l'horizon de l'être.... Thomas d'Aquin établit, sinon le premier, du moins le plus emblématiquement, que la connaissance de Dieu, même théologique, peut et doit s'accomplir dans l'horizon privilégié de l'être" (ibid., p. 315). 
Ser, esencia y atributos divinos: el conocimiento de Dios en la metafisica tomasiana

Heidegger"32. El ser de Dios mantiene su trascendencia tanto respecto del ente como respecto del ser del ente, manteniendo el carácter de mysterium tremendum. No obstante, según Marion, esto significa, para Tomás, que bajo ningún aspecto puede Dios ser concebido adecuadamente a partir de lo que hemos llamado esse. Así, el esse divino queda completamente liberado en su comprensión de lo que la filosofia entiende por "ser", "ente", "ser del ente"33. Concretamente, el ser asignado a Dios, queda liberado del ente común y creado, y, por lo tanto, de lo que nosotros comprendemos y conocemos bajo el título de "ser": Dios "sin" el ser, o el ser "fuera" del ser (al menos, de este ser, el que podemos pensar) ${ }^{34}$.

Esta tesis, según la cual el ser de Dios escaparía a toda comprensión conceptual del ser, quedaría, para Marion, confirmada a partir de la identificación entre el ser y la esencia (o quididad) que Tomás hace radicar en Dios. Ello, para el autor, equivale a decir que Dios no tiene esencia ${ }^{35} \mathrm{y}$, así, su ser se sustrae a la búsqueda metafisica, que es la búsqueda de la "esencia" (del "ser"). Resulta elocuente que Marion traiga a colación la concepción aristotélica de la metafísica, que reconduce la interrogación acerca del ente a la interrogación acerca de la esencia ${ }^{36}$. En este sentido, la ausencia de la esencia en Dios constituye una nueva confirmación de que Dios no se dice ni puede decirse según el ser tal como la metafísica lo entiende. Esta irreductibilidad del ser divino a toda esencia es, justamente, lo que hace que Dios permanezca incognoscible: en contraposición a la acepción categorial de los sentidos del "ente" según Aristóteles, la acepción del ser de Dios se caracteriza estrictamente por

\footnotetext{
32 “...Thomas d'Aquin pourrait au contraire excepter Dieu de l'être, pris non seulement au sens de la metaphysica, mais aussi au sens de l'onto-théo-logie, dans la stricte mesure où il déploie un esse radicalement différent tant de l'ens et du conceptus univocus entis que de l'être entrevu par Heidegger" (ibid., p. 320).

33 “...Penser l'esse à partir de Dieu permet à Thomas d'Aquin de libérer l'esse divin de sa compréhension -tangentiellement univoque- à partir de ce que la philosophie entend par être, étant, être de l'étant, bref, de marquer la distance -'...infinita distantia creaturae ad Deum" (ibid., p. 321).

34 “...l'esse assigné à Dieu s'excepte de l'être commun et créé, donc de ce que nous comprenons et connaissons sous le titre d'être. Dès lors, Dieu sans l'être (du moins sans cet être), pourrait devenir une thèse thomiste" (ibid., p. 322).

35 “...Sans doute Thomas d'Aquin ne ratifie-t-il pas littéralement la thèse de l'absence d'essence en Dieu ; mais le simple fait qu'il motive cette absence par sa propre thèse sur la non-composition en Dieu de l'esse et de l'essence suffit à confirmer son accord avec les 'philosophes"' (ibid., p. 323). Y más adelante: “...Sans doute qu'aucune essence (ou quidité) ne peut convenir à l'esse de Dieu, qui, par suite, reste absolument et formellement sans essence" (ibid., p. 324).

36 “....Mais, si l'on admet qu'il convient par définition (Aristote) à la métaphysique de reconduire l'interrogation sur ce qu'est l'étant à l'interrogation sur l'essence,... comment ne pas interpréter la défaillance de l'essence devant Dieu comme une nouvelle confirmation que Dieu ne se dit et ne peut se dire selon l'être tel que la métaphysique l'entend ? Un esse irréductible à toute essence signifie, en fait, un esse irréductible à l'essence métaphysique de l'être -tel qu'il se déploie ontothéologiquement" (ibid., p. 324).
} 
su incapacidad para ser conocido ${ }^{37}$. Y así, este puro ser, es tan incognoscible como el Dios que designa. El ser divino permanece sin “concepto" de ser, sin esencia, sin definición, sin cognoscibilidad, siendo un nombre negativo ${ }^{38}$. En palabras de Marion: "el esse que Tomás de Aquino reconoce a Dios no abre ningún horizonte metafísico, no pertenece a ninguna onto-teo-logía, y mantiene una tan distante analogía con todo lo que nosotros concebimos bajo el concepto de 'ser',... que -por muy paradojal que parezca-, no es"39.

\section{Algunas observaciones acerca de las tesis de Marion}

\subsection{Dios y las perfecciones absolutas}

Pasaremos, ahora, a considerar algunas de las afirmaciones de Marion, buscando determinar en qué medida estas se ajustan al pensamiento tomasiano, particularmente, en relación con la cuestión relativa a la posibilidad de un conocimiento filosófico-natural de Dios. En este sentido, la primera tesis que Marion atribuye a Tomás es que Dios, en la medida en que permanece en la posición de "principio" del objeto de la metafisica, no pertenece en cuanto tal, ni a la metaphysica, ni a su teología, ni al ens commune, ni al ens in quantum ens ${ }^{40}$. En otros términos, la teología metafísica solo estudia a Dios indirectamente en tanto "principio" de los efectos que produce y que propiamente constituyen el subjectum de la metafísica ${ }^{41}$. Pues bien, esta tesis parece tener su antecedente

\footnotetext{
37 “...L'acception d'esse propre à Dieu se caractérise strictement par son inconnaissabilité, au contraire de l'acception catégoriale, parfaitement intégrée à la pluralité métaphysique des sens de l'étant selon Aristote" (ibid., p. 324).

38 “...l'esse divin reste... sans concept d'être, sans essence, sans définition, sans connaissabilité, bref, un nom négatif" (ibid., p. 329).

39 “...l'esse que Thomas d'Aquin reconnaît à Dieu n'ouvre aucun horizon métaphysique, n'appartient à aucune onto-théo-logie et entretient une si distante analogie avec ce que nous concevons sous le concept d'être', en sorte qu'il n'en est pas, n'y est pas, voire -aussi paradoxal qu'il y paraisse- n'est pas” (ibid., p. 327).

40 “...Il faut en conclure que... Dieu n'appartient pas à la théologie métaphysique dans la mesure même où il demeure en position de principe du sujet de la métaphysique, l'étant en tant qu'étant. Ainsi, pour Thomas d'Aquin, Dieu, en tant que tel, n'appartient ni à la métaphysique, ni à sa théologie, ni à l'ens commune, ni à l'ens in quantum ens" (ibid., p. 290).

41 "La science de l'étant en tant qu'étant ne peut traiter des choses divines que dans la mesure, très étroite, où celles-ci interviennent par leurs effets selon l'étantité et comme des étants; et comme seuls leurs effets (non elles-mêmes) se disent selon l'étantité et comme des étants, il faut en conclure que les choses divines ne s'inscrivent pas directement dans la théologie de la métaphysique, ainsi qu'elles feraient si elles relevaient entièrement de l'étant commun, mais n'interviennent qu'indirectement, à titre de principe des choses (substrat), mais non comme de tels choses... “(ibid., p. 289). Y más adelante: "Pour lui [Thomas d’Aquin], Dieu, en tant que tel, n'appartient pas au sujet de la théologie métaphysique, mais reste le principe qui lui départit ce dont, selon l'étant commun, celle-ci traite, mais dont lui seul ne relève pas" (ibid., p. 293).
} 
en el pensamiento de Avicena expuesto en el Liber de philosophia prima, para quien la ciencia que llamamos Metafisica considera al "ente en tanto que ente", sin excluir a Dios, aunque no lo aborda como su subjectum, sino en calidad de "principio" (principium principiorum) que la ciencia busca o investiga ${ }^{42}$. Tomás de Aquino toma la vía aviceniana, y tal como lo atestigua el mismo Marion, en la quaestio 5 del comentario al De trinitate de Boecio, asigna a la theologia philosophica el conocimiento del ente en cuanto ente, y el conocimiento de Dios sólo en cuanto principio de ese subjectum, dejando para la theologia sacrae Scripturae el conocimiento de Dios en si mismo como de su subjectum ${ }^{43}$.

Siendo esto así, la coincidencia, empero, entre Tomás y Avicena no parece ser total en este punto. Según Castello Dubra, existiría entre ambas posiciones una diferencia, mayoritariamente asumida entre los estudiosos del pensamiento tomasiano (Wippel, Porro, Brock): a saber, que mientras para el filósofo persa, Dios, en cuanto principio, es un cierto tipo de "ente" (a saber, el "ente no causado" o "primer ente"), que termina así siendo incluido dentro de la noción común de ente que es objeto de la metafisica, para Tomás, en cambio, tal como se desprende de numerosos textos, el "ente" que es objeto de la metafísica, sería el esse commune que resulta coextensivo con el ens creatum $^{44}$. De esta

${ }^{42}$ En su Liber de philosophia prima sive scientia divina (Avicenna latinus, Liber de philosophia prima sive scientia divina, ed. Simone Van Riet, 2 vol., Louvain - Leiden: E. Peeters - E.J. Brill, 1977-1980), sostiene el filósofo persa, a saber: por un lado, que Dios no puede constituirse en objeto de la Metafísica (I, 1, p. 4, 64: "sed non potest concedi quod Deus sit in hac scientia ut subiectum"), ya que la existencia de Dios no está dada desde el comienzo de la reflexión metafísica, sino que justamente sólo se alcanza al término de ésta, y ninguna ciencia debe establecer la existencia de su propio objeto (I, 1, p. 5, 85: "nulla enim scientiarum debet stabilire esse suum subiectum"); así, aunque esta ciencia trate acerca de Dios (I, 1, p. 3, 44-46: "et etiam iam audisti quod scientia divina est in qua quaerunt de primis causis naturalis esse et doctrinalis esse et de eo quod pendet ex his, et de causa causarum et de principio principiorum, quod est Deus excelsus"), sin embargo, éste no constituye su subjectum. Por el contrario, el subjectum de la Metafisica está constituido por el "ente en tanto que ente" y todo aquello que necesariamente lo acompaña (I, 2, p. 12, 30-32: "igitur ostensum est tibi ex his omnibus quod ens, inquantum est ens, est commune omnibus his et quod ipsum debet poni subiectum huius magisterii”; I, 2, p. 13, 36-38: "ideo primum subiectum huius scientiae est ens inquantum est ens, et ea quae inquirit sunt consequentia ens inquantum est ens, sine condicione").

43 "Sic ergo theologia sive scientia divina est duplex. Una, in qua considerantur res divinae non tamquam subiectum scientiae, sed tamquam principia subiecti, et talis est theologia, quam philosophi prosequuntur, quae alio nomine metaphysica dicitur. Alia vero, quae ipsas res divinas considerat propter se ipsas ut subiectum scientiae et haec est theologia, quae in sacra Scriptura traditur" (Aquino, Tomás de, Super Boetium De Trinitate, pars 3, q. 5, a. 4). Para los textos de Tomás, se sigue de aquí en adelante la edición electrónica de la opera omnia: Corpus Thomisticum, Subsidia studii ab Enrique Alarcón collecta et edita Pompaelone ad Universitatis Studiorum Navarrensis aedes ab A.D. MM, 2000-: http://www.corpusthomisticum.org/iopera.html.

44 Castello Dubra, J., "Dios y el objeto de la metafisica: Tomás de Aquino y el Avicena latino", en: Peretó Rivas, R. (ed.), Temas de Metafísica en la Edad Media, Cuadernos medievales de Cuyo, 5 (2011), pp. 25-42, pp. 31-36. En este sentido, sostiene Ramón Guerrero en relación con la 
manera, Dios (incluido en la metafísica sólo como principio del subjectum) quedaria por fuera del esse commune, lo que permitiría al Aquinate salvar la trascendencia (o "distancia") de Dios respecto de los entes finitos, rechazando así simultáneamente la posibilidad de formación de un concepto "unívoco" de "ente" para lo creado e increado. En este punto, Marion sigue la misma línea interpretativa de los estudiosos de Tomás, separando, según nuestro criterio, con acierto, el pensamiento tomasiano de las posiciones radicalizadas de sus supuestos seguidores (como Egidio Romano, Francisco Suárez) o de la tentativa de Duns Escoto, que convierten a Dios en un "ente" entre otros entes (en sentido univoco), aunque con la prerrogativa de la "infinitud".

Sin embargo, observamos con mayor precisión que se encuentra en la intención de Marion el excluir completamente a Dios de la esfera de la metafísica, incluso como aquello estudiado a la manera de "principio" del subjectum (y asî como finis que esta ciencia debe esforzarse por conocer ${ }^{45}$ ): en efecto, no parece haber, para el autor, conocimiento posible alguno de la "causa" a partir de los efectos causados. Puesto que no solamente Dios no es un ens (en la medida en que Dios se dice propiamente esse), sino que el ser de las creaturas (el esse creado identificado con el esse commune) que de la Primera Causa depende, nada tiene de común con el esse divino ${ }^{46}$, existiría según Marion una "esencial discontinuidad", no solamente entre Dios y los entes, sino también entre Dios y el ser de los entes ${ }^{47}$. En efecto, la trascendencia de la Causa Primera, "no puede decirse ni encerrarse en el ser, pues ella se ejerce, incluso sobre él" ${ }^{\prime}$. En

concepción de Avicena: “... la metafísica aviceniana se articula y se desdobla, entonces, onto-teológicamente; ontología y teología son dos aspectos de un mismo ámbito de estudio: el ser y sus propiedades" (Guerrero, R., "Sobre el objeto de la metafísica según Avicena", en: Cuadernos de Pensamiento, 10 (1996-7), pp. 59-75, p. 75).

45 "Nam cognitio causarum alicuius generis, est finis ad quem consideratio scientiae pertingit" (Aquino, Tomás de, Sententia libri Metaphysicae [=In duodecim libros Metaphysicorum Aristotelis expositio], Proemium).

46 “... La causalité éloigne ensuite parce que, si elle permet et impose une fondation des étants par une cause (Begründung), néanmoins cette fondation ne provient pas d'un étant, suprême, ou par excellence, puisque Dieu se dit proprement esse et non pas ens; ensuite, cette fondation ne se limite pas aux étants créés, mais remonte jusqu'à leur être...; surtout, cette fondation n'autorise aucune fondation réciproque et en retour, sous la figure de la fondation (Gründung) de l'étant suprême (d'ailleurs manquant) par et selon son être, puisque l'esse commune n'a rien de commun avec un tel esse divin, et que celui-ci n'admet ni ne requiert aucune fondation" (Marion, J.-L., Dieu sans l'être, 2002, p. 309).

47 “Entre l'éventuel être de Dieu et l'étantité des étants qu'il cause comme son principe, intervient une essentielle discontinuité : non seulement entre Dieu et les étants, mais aussi bien entre Dieu et l'être de ces étants" (ibid., p. 307).

48 “... sa transcendance [de la Causa prima] ne peut se dire ni se cantonner dans l'être ; donc elle s'exerce même sur lui" (ibid., p. 307). 
torno a esto agrega Marion que, mientras el ser de la metafísica, en su inteligibilidad, es trazado por la representación del entendimiento humano, el ser de Dios, en la medida en que se independiza de la metafísica, se libera también de su tipo de inteligibilidad, mostrándose así Dios como algo completamente desconocido (inconnu) ${ }^{49}$.

Ahora bien, frente a estas tesis (a saber: que Dios no es un "ente" cognoscible a partir de los entes, y que el ser de Dios nada tiene que ver con el esse de las creaturas, de manera que existe entre ellos una "esencial discontinuidad") no podemos dejar de notar una cierta "tensión" respecto de otras tesis que se afirman sin ninguna ambigüedad en otros textos del Aquinate. En primer lugar, que es posible atribuir a Dios lo que le corresponde al ens inquantum ens. Un pasaje de gran contundencia pertenece al capítulo 52 del libro II de la Suma contra gentiles, en el que el Aquinate afirma de manera inequívoca que al esse per se subsistens se le atribuye lo que le corresponde al ente en tanto que ente: "si sit aliquod esse per se subsistens, nihil competit ei nisi quod est entis inquantum est ens"50. En efecto, tal como demuestra Castello Dubra en su artículo acerca de la concepción de la metafisica en Tomás y el Avicena latino, "es posible rastrear algunas argumentaciones en las que Aquino parece retomar la distinción aviceniana entre el ente que es causado y el ente que no tiene causa, o en las que extiende a Dios las propiedades del ente en tanto que ente"51. De esta manera, si existe "una distancia infinita que separa al ser subsistente por sí del ente que no es su ser, sino que tiene el ser por participación, habría que insistir en que ello, al parecer, no obsta para atribuir al ser subsistente lo que le cabe al ente en cuanto ente"52.

En este sentido, nos parece que la noción de "analogia" que propone Marion, aunque acertadamente busca oponerse a una concepción univoca del ente que, creemos, no existe en el pensamiento del Aquinate, no logra sin embargo dar cuenta de la afirmación tomasiana recién esbozada (Summa contra gentiles, II, C. 52). Pues quedando Dios totalmente separado del ente y del ser del ente (creado), no se ve cómo sería posible para Tomás predicar de Dios las

\footnotetext{
49 “... l'esse propre à Dieu seul, en s'arrachant de la métaphysique, se libère aussi de son type d'intelligibilité, jusqu'à apparaître, à son égard, rien de moins qu'inconnu" (ibid., p. 296). También: ibid., p. 301.

50 Aquino, Tomás de, Summa contra Gentiles, 1. II, c. 52.

51 Castello Dubra, Julio A., "Dios y el objeto de la metafisica: Tomás de Aquino y el Avicena latino", p. 37.

52 Ibid., p. 39.
} 
mismas propiedades que se dicen del "ente". En efecto, en la teología metafisica atribuimos a Dios ciertas perfecciones positivas como "sabio", "justo", "bello": estos nombres corresponden a ciertas propiedades o perfecciones absolutas que encontramos en las cosas creadas, pero que predicamos de Dios en la medida en que significan, de algún modo, la misma substancia divina ${ }^{53}$. Entre estos términos ubicamos por ejemplo a los trascendentales como "ente", "verdadero", "bueno", pero también a los atributos llamados "operativos", como la "inteligencia" y la "voluntad" y demás cualidades. Pues bien, en relación a éstos, Tomás ha afirmado en distintos lugares de su obra, dos tesis especialmente importantes para nuestro propósito: por un lado, que estos nombres se dicen de Dios en sentido propio (proprie) - y no meramente metafórico -, y por el otro, que se dicen de Dios substantialiter, esto es, que significan la misma sustancia divina, aunque imperfectamente.

A este respecto, particularmente elocuentes son los pasajes de la quaestio 13 de la Prima Pars de la Summa theologiae. Allí, en el artículo 3, Tomás explicita la diferencia entre los nombres que no pueden ser aplicados a Dios más que metafóricamente (como el nombre de "piedra", que expresa una realidad material y así su significación incluye intrínsecamente un modo imperfecto) y los nombres que pueden serle atribuidos a Dios en sentido propio (como los nombres "ente", "bueno", "viviente", que expresan perfecciones absolutas, sin que su significación incluya algún modo de participación) ${ }^{54}$. Ahora bien, en relación con estos últimos, debe tenerse en cuenta que solo en lo que respecta a lo que significan tales nombres (res significata), pueden decirse de Dios propiamente (proprie) y, además, en primer lugar de Él (per prius) -y no de las creaturas-. Pues en lo que se refiere al modo de significación (modus significandi), no se dicen de Dios en sentido propio, ya que el modo de significación les corresponde a las creaturas. En efecto, aunque tales perfecciones sean más sublimes en Dios que en las creaturas, nuestro intelecto las aprehende tal como están en las cosas

\footnotetext{
53 “...Et ideo aliter dicendum est, quod huiusmodi quidem nomina significant substantiam divinam, et praedicantur de Deo substantialiter, sed deficiunt a repraesentatione ipsius" (Aquino, Tomás de, Summa Theologiae, I, q. 13, a. 2).

54 “...Ad primum ergo dicendum quod quaedam nomina significant huiusmodi perfectiones a Deo procedentes in res creatas, hoc modo quod ipse modus imperfectus quo a creatura participatur divina perfectio, in ipso nominis significato includitur, sicut lapis significat aliquid materialiter ens, et huiusmodi nomina non possunt attribui Deo nisi metaphorice. Quaedam vero nomina significant ipsas perfectiones absolute, absque hoc quod aliquis modus participandi claudatur in eorum significatione, ut ens, bonum, vivens, et huiusmodi, et talia proprie dicuntur de Deo" (ibid., I, q. 13, a. 3, ad 1).
} 
creadas, en la medida en que conocemos a Dios a partir de las perfecciones que, procedentes de Él, se encuentran en las creaturas ${ }^{55}$.

Pero otro punto es igualmente importante, a saber: que estos nombres expresan la sustancia divina y se predican de Dios sustancialmente (substantialiter), aunque no la expresen perfectamente ${ }^{56}$. Por un lado, esto significa que, cuando decimos de Dios, por ejemplo, que es "viviente", no queremos expresar con esto algo que Dios no tiene o no es (a saber, que no es una cosa inanimada), sino más bien algo que Dios tiene o es positivamente. Por el otro lado, significa, también, que cuando decimos, por ejemplo, que Dios es "bueno", no nos referimos a la relación causal entre Dios y las creaturas como si buscáramos simplemente establecer que Dios es la Causa de la bondad de las $\operatorname{cosas}^{57}$. Esto se debe a que "[loquentes de Deo] aliud intendunt dicere, cum dicunt Deum viventem, quam quod sit causa vitae nostrae, vel quod differat a corporibus inanimatis"58. Estos

\footnotetext{
55 "Respondeo dicendum quod, sicut dictum est, Deum cognoscimus ex perfectionibus procedentibus in creaturas ab ipso; quae quidem perfectiones in Deo sunt secundum eminentiorem modum quam in creaturis. Intellectus autem noster eo modo apprehendit eas, secundum quod sunt in creaturis, et secundum quod apprehendit, ita significat per nomina. In nominibus igitur quae Deo attribuimus, est duo considerare, scilicet, perfectiones ipsas significatas, ut bonitatem, vitam, et huiusmodi; et modum significandi. Quantum igitur ad id quod significant huiusmodi nomina, proprie competunt Deo, et magis proprie quam ipsis creaturis, et per prius dicuntur de eo. Quantum vero ad modum significandi, non proprie dicuntur de Deo, habent enim modum significandi qui creaturis competit" (ibid., I, q. 13, a. 3).

56 "Et ideo aliter dicendum est, quod huiusmodi quidem nomina significant substantiam divinam, et praedicantur de Deo substantialiter, sed deficiunt a repraesentatione ipsius. Quod sic patet. Significant enim sic nomina Deum, secundum quod intellectus noster cognoscit ipsum. Intellectus autem noster, cum cognoscat Deum ex creaturis, sic cognoscit ipsum, secundum quod creaturae ipsum repraesentant.... Sic igitur praedicta nomina divinam substantiam significant, imperfecte tamen, sicut et creaturae imperfecte eam repraesentant" (ibid., I, q. 13, a. 2).

57 "Quidam enim dixerunt quod haec omnia nomina, licet affirmative de Deo dicantur, tamen magis inventa sunt ad aliquid removendum a Deo, quam ad aliquid ponendum in ipso. Unde dicunt quod, cum dicimus Deum esse viventem, significamus quod Deus non hoc modo est, sicut res inanimatae, et similiter accipiendum est in aliis. Et hoc posuit Rabbi Moyses. Alii vero dicunt quod haec nomina imposita sunt ad significandum habitudinem eius ad creata, ut, cum dicimus Deus est bonus, sit sensus, Deus est causa bonitatis in rebus. Et eadem ratio est in aliis. Sed utrumque istorum videtur esse inconveniens, propter tria. Primo quidem, quia secundum neutram harum positionum posset assignari ratio quare quaedam nomina magis de Deo dicerentur quam alia. Sic enim est causa corporum, sicut est causa bonorum, unde, si nihil aliud significatur, cum dicitur Deus est bonus, nisi Deus est causa bonorum, poterit similiter dici quod Deus est corpus, quia est causa corporum. Item, per hoc quod dicitur quod est corpus, removetur quod non sit ens in potentia tantum, sicut materia prima. Secundo, quia sequeretur quod omnia nomina dicta de Deo, per posterius dicerentur de ipso, sicut sanum per posterius dicitur de medicina, eo quod significat hoc tantum quod sit causa sanitatis in animali, quod per prius dicitur sanum. Tertio, quia hoc est contra intentionem loquentium de Deo. Aliud enim intendunt dicere, cum dicunt Deum viventem, quam quod sit causa vitae nostrae, vel quod differat a corporibus inanimatis" (ibid., I, q. 13, a. 2).

58 Ibid., I, q. 13, a. 2.
} 
nombres, por el contrario, designan el mismo principio de las perfecciones y, así, la vida o la bondad, en tanto preexisten en Dios de un modo más sublime. De esta manera, al afirmar "Dios es bueno", el sentido de esta frase no es "Dios es causa de la bondad" o "Dios no es malo", sino "lo que llamamos bueno en las creaturas, preexiste en Dios, de manera sublime", y, así, solo "en la medida en que Dios es bueno, existimos"59.

Ahora bien, estas tesis no parecen encuadrarse exactamente en la línea explicativa de Marion. En efecto, cuando considera la segunda característica de la onto-teo-logía, a saber, la causalidad eficiente de los entes por parte de Dios ("ente" supremo), el autor repara brevemente en los nombres que se dicen de Dios a partir de las creaturas, esto es, a partir de sus efectos. Según este segundo criterio, la causalidad eficiente permite conocer al Creador en tanto causa y solo bajo la relación de causalidad. De acuerdo con ello, sostiene, los nombres atribuidos a Dios "solo pueden remontar a Él con ese mínimo de no-impropiedad, que los libera de la pura y simple equivocidad"60, en la medida en que "la relación causal les garantiza que, al menos según la eficiencia, llevan la marca de su causa”61. De esta manera, “...'lo bueno', 'lo bello', 'lo verdadero', no dicen sin duda nada acerca de la bondad, la verdad y la belleza divinas, sino que provienen de ellas por eficiencia indiscutible, aunque abstracta y sin contenido real" 62 . En este sentido, al entender que existe, en Tomás, una comprensión distinta de la "causalidad" (la de la causa en el sentido de Dionisio) ${ }^{63}$, Marion sostiene que, para el dominico, de ninguna manera las cosas causadas pueden remitirnos cognoscitivamente a Dios, ya que permanecen infinitamente excedidas por la Causa Primera ${ }^{64}$ : las creaturas constituyen, entonces, los efectos

\footnotetext{
59 "Cum igitur dicitur Deus est bonus, non est sensus, Deus est causa bonitatis, vel Deus non est malus, sed est sensus, id quod bonitatem dicimus in creaturis, praeexistit in Deo, et hoc quidem secundum modum altiorem. Unde ex hoc non sequitur quod Deo competat esse bonum inquantum causat bonitatem, sed potius e converso, quia est bonus, bonitatem rebus diffundit, secundum illud Augustini, de Doct. Christ., inquantum bonus est, sumus" (ibid., I, q. 13, a. 2).

${ }^{60}$ Marion, J.-L., Dieu sans l'être, 2002, p. 302.

61 “...les noms attribués à Dieu ne valent évidemment comme tels que des effets dont ils viennent ; ils ne peuvent remonter à Dieu avec ce minimum de non-impropriété, qui les arrache à la pure et 170 simple équivocité, qu'autant que la relation causale leur garantit qu'au moins selon l'efficience ils portent la marque de leur cause" (Marion, J.-L., Dieu sans l'être, 2002, p. 302).

62 “...'bon', 'beau', 'vrai', ne disent sans doute rien de la bonté, de la vérité et de la beauté divines, sinon qu'ils en proviennent par efficience indiscutable, mais abstraite, sans contenu réel" (ibid., p. 302).

${ }_{63}$ Para las correcciones que Tomás habría introducido en la noción de "causalidad" según Marion, ver los desarrollos del punto 5, "La cause et la fondation" del capítulo que estamos analizando: ibid., p. 301.

64 "De ces deux corrections apportées à la causalité, il s'ensuit une conséquence capitale: l'intelligibilité abstraite, transparente et éventuellement univoque de l'efficience le cède, pour Thomas
} 
conocidos de una causa absolutamente desconocida ${ }^{65}$. En consecuencia, el pensamiento tomasiano quedaría liberado de la onto-teo-logía.

Sin embargo, estas afirmaciones de Marion, no parecen guardar completa sintonía con los textos que hemos estado analizando. El Aquinate no solo admite que estos nombres (como "bueno", "bello", "verdadero") se predican de Dios de manera "no-equivoca" y "no-impropia", sino que incluso -sostiene- se dicen de Él proprie, per prius y substantialiter, superando, así, ampliamente ese "mínimo de no-impropiedad que los libera de la pura y simple equivocidad". En efecto, se trata de nombres que, según lo que significan (res significata) y, así, en su "contenido real", se predican propiamente y en primer lugar de Dios, lo que expresa la misma substancia divina de manera positiva, aunque imperfecta. Tanto es así que el Aquinate aclara que, cuando decimos de Dios que es "bueno", no queremos simplemente establecer que Dios no es malo (caracterizándolo negativamente) o que es la causa de la bondad de las cosas (caracterizándolo por los efectos que produce), sino que en Dios se da esta perfección absoluta de manera sublime ${ }^{66}$ : en efecto, como él mismo lo explica, estos nombres son dichos de Dios no solo en sentido causal (causaliter), sino también esencial (essentialiter $)^{67}$.

d'Aquin, (et au contraire de ses successeurs), à une causalité normée par la relation de création, c'est-à-dire, telle que les causés, s'ils se fondent réellement dans la cause, se trouvent en retour infiniment excédés par elles... bien que totalement déterminés par elle, ou pour cela même, ils lui restent définitivement inadéquats" (ibid., p. 304). Y más adelante: "La cause peut donc bien rester inconnue comme telle, parce que, si elle se laisse connaitre comme fondant ses effets, elle n'en reçoit pourtant aucune fondation qui la rendrait réciproquement intelligible" (ibid., p. 305).

65 “...Si Dieu, en tant que cause non réciproque, excède l'esse au titre d'une première créature, il faut comprendre précisément que l'être, aussi originel qu'il nous demeure, reste, malgré ou pour cela même a parte Dei second, régional, hypothétique, sous condition, bref qu'il nous advient comme l'effet connu de cause inconnue" (ibid., p. 308).

66 "....Sic igitur dicendum est quod huiusmodi divina nomina imponuntur quidem a processibus deitatis, sicut enim secundum diversos processus perfectionum, creaturae Deum repraesentant, licet imperfecte; ita intellectus noster, secundum unumquemque processum, Deum cognoscit et nominat. Sed tamen haec nomina non imponit ad significandum ipsos processus, ut, cum dicitur Deus est vivens, sit sensus, ab eo procedit vita, sed ad significandum ipsum rerum principium, prout in eo praeexistit vita, licet eminentiori modo quam intelligatur vel significetur" (Aquino, Tomás de, Summa Theologiae, I, q. 13, a. 2, ad 2).

67 “...Sed supra ostensum est quod huiusmodi nomina non solum dicuntur de Deo causaliter, sed etiam essentialiter. Cum enim dicitur Deus est bonus, vel sapiens, non solum significatur quod ipse sit causa sapientiae vel bonitatis, sed quod haec in eo eminentius praeexistunt. Unde, secundum hoc, dicendum est quod, quantum ad rem significatam per nomen, per prius dicuntur de Deo quam de creaturis, quia a Deo huiusmodi perfectiones in creaturas manant. Sed quantum ad impositionem nominis, per prius a nobis imponuntur creaturis, quas prius cognoscimus. Unde et modum significandi habent qui competit creaturis, ut supra dictum est" (ibid., I, q. 13, a. 6). 
En este sentido, para nuestro propósito, resulta particularmente interesante la reflexión de Castello Dubra acerca de la predicación de los atributos divinos en Tomás de Aquino: predicar de Dios substancialmente y en sentido propio implica, precisamente, "predicar realmente algo de Dios", esto es, que "al contenido conceptual de los predicados que le atribuimos a Dios les corresponda, en algún sentido, algo existente en la realidad misma que es Dios, a fin de que la predicación pueda ser verdadera"68. De esta manera, nos parece que el sentido otorgado al concepto de "analogía" en Tomás no debería hacer caso omiso del hecho de que para el Aquinate existe un conocimiento filosóficonatural real-verdadero de Dios, a pesar de que al mismo tiempo, como afirma Castello Dubra, dicha scientia esté atravesada por la inconmensurabilidad de su objeto, el cual "permanece incomprendido aún después de realizada esa ciencia verdadera" ${ }^{\prime}$. Volveremos sobre este punto más adelante.

\subsection{Dios y la esencia}

Ahora bien, en la línea de las reflexiones precedentes, resulta importante analizar otra cuestión que apenas hemos esbozado, pero que creemos juega un rol central en la reflexión de Marion acerca de la distinción entre el esse de la creatura y el esse divino. La cuestión a la que nos referimos es la comprensión y la utilización que el autor hace de la tesis tomasiana de la "distinción real" de esencia y ser en la creatura, y la correlativa tesis de la "indistinción" o "identidad real" en Dios. Acerca de ésta última, Marion destaca aquel pasaje del $D e$ ente et essentia en el que el Aquinate sostiene que hay "algo" como Dios, cuya esencia es su propio ser, y que por esta razón algunos filósofos dicen que Dios no tiene quididad o esencia, ya que su esencia no es otra cosa que su ser ${ }^{70}$. Esta tesis atribuida a los "filósofos" correspondería, como el mismo Marion lo atestigua, al pensamiento de Avicena ${ }^{71}$.

No obstante, el punto interesante radica en lo que Marion sostiene en relación con ella, a saber, que, aunque "Tomás de Aquino no ratifique literalmente la tesis de la ausencia de esencia en Dios"72, "el simple hecho de que justifique esta ausencia a través de su propia tesis sobre la no-composición

${ }^{68}$ Castello Dubra, Julio A., "La predicación de los atributos divinos en Tomás de Aquino", en: Analytica, XIV, 2 (2010), pp. 89-107, p. 104.

${ }^{69}$ Ibid., p. 104.

70 "Aliquid enim est, sicut Deus, cuius essentia est ipsummet suum esse; et ideo inveniuntur aliqui philosophi dicentes quod Deus non habet quiditatem vel essentiam, quia essentia sua non est aliud quam esse eius" (Aquino, Tomás de, De ente et essentia, c. IV).

${ }_{71}^{71}$ Marion, J.-L., Dieu sans l'être, p. 323.

${ }^{72}$ Ibid. 
en Dios del esse y la esencia, resulta suficiente para confirmar su acuerdo con los "filósofos""73: de esta manera, Dios permanecería absoluta y formalmente sin esencia ${ }^{74}$. Esta doctrina resulta fundamental a los ojos de Marion, ya que, según él, permitiría, nuevamente, liberar al esse divino del esse creado y de su inteligibilidad trazada por la representación del entendimiento humano y desligar, así, el pensamiento de Tomás en torno a lo divino de los parámetros impuestos por la onto-teo-logía y la metaphysica. En efecto, sostiene el autor: “...si se admite que conviene por definición (Aristóteles) a la metafísica reconducir la interrogación sobre qué es el ente a la interrogación sobre la esencia..., ¿cómo no interpretar la deficiencia de la esencia en Dios como una nueva confirmación de que Dios no se dice y no puede decirse según el ser tal y como la metafisica lo entiende? Un esse irreductible a toda esencia, significa, de hecho, un esse irreductible a la esencia metafisica del ser -tal y como se despliega onto-teo-lógicamente"75.

Así pues, la afirmación de la ausencia de una esencia en Dios le permitiría a Tomás deslindarse del horizonte de comprensión inaugurado por la metafísica aristotélica, que reconduce el ser a la esencia ${ }^{76}$ y que, por ello, no puede pensar a Dios sino a partir del "ente". En efecto, esta irreductibilidad tomasiana del esse divino a la esencia, por lo que el ser de Dios se constituye como un esse puro o acto puro de ser (supuestamente) carente de esencia, garantizaria la incognoscibilidad absoluta de Dios. Ello "significa”, en palabras de Marion, "la imposibilidad de articularlo predicativamente, de decirlo discursivamente, en fin, de comprenderlo"77. Tanto es esto así que, cuando predicamos de Dios el "ser",

\footnotetext{
73 “...Sans doute Thomas d'Aquin ne ratifie-t-il pas littéralement la thèse de l'absence d'essence en Dieu; mais le simple fait qu'il motive cette absence par sa propre thèse sur la non-composition en Dieu de l'esse et de l'essence suffit à confirmer son accord avec les 'philosophes"' (ibid.).

74 “...Sans doute qu'aucune essence (ou quidité) ne peut convenir à l'esse de Dieu, qui, par suite, reste absolument et formellement sans essence" (ibid., p. 324).

75 “...Mais, si l'on admet qu'il convient par définition (Aristote) à la métaphysique de reconduire l'interrogation sur ce qu'est l'étant à l'interrogation sur l'essence,... comment ne pas interpréter la défaillance de l'essence devant Dieu comme une nouvelle confirmation que Dieu ne se dit et ne peut se dire selon l'être tel que la métaphysique l'entend ? Un esse irréductible à toute essence signifie, en fait, un esse irréductible à l'essence métaphysique de l'être -tel qu'il se déploie ontothéologiquement" (ibid., p. 324).

${ }^{76}$ Metafisica, VII, 1, 1028b2-4. Aristóteles, Aristotle's Metaphysics, (ed.) Ross, W.D., Oxford: Clarendon Press, 1924, VII, 1, 1028b2-4. De aquí en adelante: Aristóteles, Metafísica.

77 “...l'irréductibilité de l'esse à toute essence signifie l'impossibilité de l'articuler prédicativement, donc de le dire discursivement, bref de le comprendre; ainsi ce pur esse se révèle-t-il en principe aussi inconnaissable que le Dieu qu'il désigne. Dieu connu comme inconnu implique ainsi que son esse ne reste connaissable que comme inconnaissable" (ibid., p. 324). Y más adelante: “...En tant qu'acte pur d'être, sans aucune référence à la composition ordinaire propre à l'étant métaphysique, l'esse divin reste aussi inconnu que Dieu, auquel précisément il revient... “ (ibid., p. 325).
} 
debemos entender por "ser" algo tan distante de lo que nosotros concebimos bajo el concepto de "ser", que, de alguna manera, sería más apropiado decir de Dios que no $\mathrm{es}^{78}$. A nuestro modo de ver, es manifiesto que aquí Marion opera exclusivamente con un concepto predicamental del "ente" y el "ser" y, también, unívoco de la "esencia". De allí la urgencia de separar estas nociones de Dios, así concebidas: "la acepción del esse de Dios se caracteriza estrictamente por su incognoscibilidad, al contrario de la acepción categorial, perfectamente integrada en la pluralidad metafisica de sentidos del ente según Aristóteles"79.

En efecto, Marion parece tener presente aquí la concepción aristotélica del "ente" en su división categorial, según la cual existirian diez modos fundamentales e irreductibles de poseer el "ser", es decir, la substancia y los nueve accidentes. Sin embargo, ya desde el comienzo del libro VII de la Metafisica, el Estagirita sostiene que el sentido fundamental de "ser" es el de la ousía, de manera que la pregunta acerca de "qué sea el ente" debe ser referida a la pregunta por la "substancia" 80 : concentrar entonces la atención sobre la sustancia significa ir al corazón del ser, a lo profundo, al principio del cual todo lo demás depende, de manera tal que estudiando la "substancia", estudiamos al ente en tanto ente ${ }^{81}$. Es así como la "ontologia" se determina como una "ousiologia". No obstante, esta descripción no estaría completa si no se especificara, al mismo tiempo, qué es la ousía. Pues bien, de los cuatro "candidatos" que propone Aristóteles (el sustrato o materia, el universal, la esencia o la forma y finalmente el compuesto de materia y forma), el filósofo griego concluye que solo la forma (lógos) y el compuesto (súnolon) son substancias ${ }^{82}$, siendo la forma (eîdos) aquella causa que hace que la materia sea algo determinado ${ }^{83}$. Es, justamente, de esta "substancia”, que es la forma o quididad (tò tî ên eînaì), de la que hay propiamente "definición" (orismós) ${ }^{84}$, como por ejemplo, del alma en el caso del hombre ${ }^{85}$.

\footnotetext{
78 “...l'esse que Thomas d'Aquin reconnaît à Dieu n'ouvre aucun horizon métaphysique, n'appartient à aucune onto-théo-logie et entretient une si distante analogie avec ce que nous concevons sous le concept d'être', en sorte qu'il n'en est pas, n'y est pas, voire -aussi paradoxal qu'il y paraisse- n'est pas” (ibid., p. 327). Concretamente: “...l'esse ne désigne Dieu que dans la stricte mesure où il le dit sans l'être" (ibid., p. 328).

$174 \quad 79$ “....'acception d'esse propre à Dieu se caractérise strictement par son inconnaissabilité, au contraire de l'acception catégoriale, parfaitement intégrée à la pluralité métaphysique des sens de l'étant selon Aristote" (ibid., p. 324).

${ }^{80}$ Aristóteles, Metafísica, VII, 1, 1028a13-15; VII, 1, 1028b2-4.

${ }^{81}$ Para este tema, ver: Berti, Enrico, Estructura y significado de la 'Metafisica' de Aristóteles, Buenos Aires: Oinos, 2011, pp. 93 y ss.

${ }^{82}$ Aristóteles, Metafisica, VII, 15, 1039b20-22.

83 Ibid., 17, 1041b7-9.

${ }^{84}$ Ibid., 5, 1031a12-14; VII, 5, 1031a17-18.

${ }^{85}$ Ibid., VII, 11, 1037a26-30.
} 
Ahora bien, si, como creemos, para Marion el ser accesible al hombre no es sino el ser del ente (predicamentalmente considerado), comprensible únicamente a partir de la esencia (de la substancia), la cual por definición constituye aquello propiamente cognoscible en tanto conceptualizable y definible, queda claro, entonces, que se hace necesario excluir a Dios de la esfera del ente, de la esencia y, en realidad, también del ser. Esto último sería imprescindible, pues la realidad de Dios no se deja incluir en ninguna de las diez categorias, ni siquiera en la de substancia y, menos aun, se presta a "definición" por género próximo y diferencia específica. Así concebidos el "ente", el "ser" y la "esencia", la posición de Marion resulta inobjetable. Empero, estas tesis pueden ser relativizadas si se analizan ciertos textos de Tomás en los que aparece un sentido "análogo" y "trascendental" del "ente", la essentia y demás términos (incluido el de "substancia"), que no se deja encerrar en el esquema aristotélico. En este sentido, aunque también Aristóteles haya afirmado que el ser no es un "género"86 y que no se predica de la substancia y los accidentes de manera unívoca, sino según una cierta homônumia pros hen (homonimia relativa a uno) ${ }^{87}$, la concepción tomasiana parece superar esta inicial "analogía" aristotélica, que se limita al plano horizontal o predicamental del ente y que encuentra, en la categoría de la substancia, su analogado principal.

Un buen ejemplo de aplicación vertical o trascendental de la analogía, esto es, entre Dios y las creaturas, está constituido por los análisis del De ente et essentia. Tal como advierten algunos autores, ya en esta obra de juventud, Aquino esboza una concepción del "ente" y la "esencia" que revela a estos términos como "análogos" 88 . En efecto, al inicio de esta obra el Aquinate se

\footnotetext{
${ }^{86}$ Aristóteles, Metafísica, III, 3, 998b22.

${ }^{87}$ Ver a este respecto: Berti, E., Estructura y significado de la 'Metafísica' de Aristóteles, pp. 76-79.

88 Así, por ejemplo, Eudaldo Forment: "Como el ente con este significado estricto, que es el propio, se divide en diez géneros, podría pensarse que hay que buscar una definición de esencia que abarque a cada una de las de estos géneros. La esencia sería entonces lo común a todas las esencias que están en los diez géneros supremos, igual que lo sería el concepto de ente que los incluye. Pero no se da algo común a las categorías, que las englobe totalmente, y que sea, por tanto, más supremo que ellas. Lo que sí hay es un concepto de ente que se predica analógicamente de todos los géneros supremos, de manera que en cada uno de ellos se realiza la entidad, pero de una manera analógica o proporcional. Porque tal concepto de ente, no es un género; lo son, en cambio, las categorías, y ya no se puede encontrar otro superior. El concepto de ente es único, pero no unívoco como todos los géneros, sino analógico. Cuando se dice que el ente se divide en diez géneros no se indica como un género en otros subgéneros, sino como un concepto análogo se divide en sus analogados. Tampoco puede considerarse la esencia como un género supremo, que comprenda todas las demás. No es algo común a la esencia de todos los géneros. Su concepto es también analógico y solo puede definirse como lo común a todas las naturalezas que están en un mismo género" (Forment, Eudaldo, Filosofía del ser. Introducción, comentario, texto y traducción del 'De ente et essentia' de Santo Tomás, Barcelona: PPU, 1988, p. 80).
} 
propone determinar el sentido de ciertos nombres fundamentales -como el de ens y essentia- para evitar, de esta manera, su uso ambiguo y, así, el error ${ }^{89}$. En relación con el primero, sostiene que el "ente" en sentido propio es dicho de dos maneras: de un modo, en cuanto es dividido en diez géneros, y de otro modo, en cuanto significa la verdad de las proposiciones ${ }^{90}$. En este sentido, solo puede llamarse "ente", según el primer modo, a aquello que pone algo en la realidad extra-mental (aliquid in re ponit), de manera tal que, según este primer modo, ni la ceguera ni cosas parecidas a ésta pueden ser llamadas "entes" Ahora bien, precisa Tomás, el nombre de "esencia" no es tomado del ente en el segundo modo dicho, ya que, según este modo, algunas cosas son llamadas entes y, sin embargo, no poseen esencia, como en el caso de las privaciones. Al contrario, la esencia es tomada del ente en el primer modo dicho (sumitur essentia $a b$ ente primo modo dicto), y es por esto que el Comentador sostiene que el ente entendido en el primer modo significa la esencia de la cosa ${ }^{92}$.

Además, es, justamente, en la significación que Tomás atribuye al término essentia en donde, según J. Maritain, se pone de manifiesto el sentido "análogo" del término, pues al ser el "ente" aquello que se divide por los diez géneros, se sigue que la esencia significa algo común a todas las naturalezas (aliquid commune omnibus naturis) según las cuales los distintos entes son colocados en los diversos géneros y especies ${ }^{93}$. Así pues, en la interpretación de Maritain, el hecho de que la noción de esencia se extienda a través de las diez categorias de Aristóteles constituye la prueba de que es una noción análoga, pues, de lo contrario, ella quedaría encerrada en un género, en alguna de las diez categorías ${ }^{94}$. Al ser, entonces, análoga, esta noción podrá “emigrar" hasta la causa del

\footnotetext{
89 Aquino, Tomás de, De ente et essentia, Prooemium.

90 "Sciendum est igitur quod, sicut in V metaphysicae philosophus dicit, ens per se dicitur dupliciter, uno modo quod dividitur per decem genera, alio modo quod significat propositionum veritatem" (ibid., c. 1).

91 "Sed primo modo non potest dici ens nisi quod aliquid in re ponit. Unde primo modo caecitas et huiusmodi non sunt entia" (ibid., c. 1).

92 "Nomen igitur essentiae non sumitur ab ente secundo modo dicto, aliqua enim hoc modo dicuntur entia, quae essentiam non habent, ut patet in privationibus; sed sumitur essentia ab 176 ente primo modo dicto. Unde Commentator in eodem loco dicit quod ens primo modo dictum est quod significat essentiam rei" (ibid., c. 1).

93 "Et quia, ut dictum est, ens hoc modo dictum dividitur per decem genera, oportet quod essentia significet aliquid commune omnibus naturis, per quas diversa entia in diversis generibus et speciebus collocantur, sicut humanitas est essentia hominis, et sic de aliis" (ibid., c.1).

94 "On voit donc que tout de suite S. Thomas affirme l'analogicité de la notion d'essence, puisque la notion d'essence se retrouve à travers les dix catégories d'Aristote ; si elle était enfermée dans un genre, elle serait enfermée dans une de ces dix catégories, c'est bien la preuve qu'elle est une notion non pas prédicamentale, mais analogique" (Maritain, J., "Sur la doctrine de l'Aséité divine", en: Mediaeval studies, V (1943), pp. 39-50, p. 45).
} 
ente, de manera tal que permanezca válida no solo en su aplicación horizontal a los entes creados, sino en relación con el ser Increado, que se encuentra por encima de toda definición humana. En efecto, sostiene el autor, si se dice que Dios no tiene esencia, es porque se posee una concepción univoca de la esencia, siendo que, en verdad, ésta constituye una noción esencialmente análoga ${ }^{95}$.

No obstante, por otro lado, también la essentia revela un carácter "trascendental", que queda determinado por su intima significación. En este sentido, la distinción semántica que establece Tomás entre los diversos nombres que se proponen para la "esencia", tiene una importancia capital. En efecto, Aquino advierte que el nombre de essentia fue cambiado por los filósofos por el nombre de quiditas, queriendo significar "aquello por lo cual la cosa es constituida en su propio género y especie", esto es, "aquello significado por la definición que indica qué es la cosa"96. Y ello quiere decir, por otra parte, lo que Aristóteles llama frecuentemente quod quid erat esse: aquello por lo que algo tiene el ser algo (hoc per quod aliquid habet esse quid) ${ }^{97}$. Por otra parte, también se le ha dado a la esencia los nombres de forma (en cuanto significa la certitudo de cada cosa) y de natura (en cuanto está ordenada a la propia operación de la cosa $)^{98}$. Sin embargo, el nombre de essentia ha sido impuesto para expresar fundamentalmente otra cosa: que por ella y en ella el ente tiene ser (sed essentia dicitur secundum quod per eam et in ea ens habet esse)99. En otros términos, la "esencia" sería aquello según lo cual el ente tiene el ser, y es este el aspecto "común" a todas las naturalezas que pone de manifiesto el nombre de essentia.

Establecidas estas distinciones entre los diversos nombres, pareciera, entonces, que el término essentia no debiera quedar necesariamente definido por la aptitud para ser objeto de una definición. Ello significa que, aunque a muchas esencias -a saber, las de los entes finitos- les correspondiera una

\footnotetext{
95 “...[la notion d'essence] pourra donc, puisqu'elle est analogue, émigrer, si je puis ainsi parler, jusqu'à la cause de l'être, elle pourra donc demeurer valable si on l'applique non seulement à l'être créé, mais à l'être incréé qui est au-dessus de toute définition humaine, mais qui peut se dire lui-même à lui-même. Si donc, on dit que Dieu n'a pas d'essence, c'est qu'on se fait de l'essence une conception univoque, alors que c'est une notion essentiellement analogique" (ibid., p. 45).

96 "Et quia illud, per quod res constituitur in proprio genere vel specie, est hoc quod significatur per diffinitionem indicantem quid est res, inde est quod nomen essentiae a philosophis in nomen quiditatis mutatur. (Aquino, Tomás de, De ente et essentia, c.1). Y más adelante: "Quiditatis vero nomen sumitur ex hoc, quod per diffinitionem significatur" (ibid., c. 1)."

97 “"Et hoc est quod philosophus frequenter nominat quod quid erat esse, id est hoc per quod aliquid habet esse quid" (Aquino, Tomás de, De ente et essentia, c. 1).

98 Ibid., c. 1.

99 Ibid., c. 1.
} 
quididad definible, este rasgo no constituiria una nota perteneciente a la esencia en cuanto essentia. Al contrario, parece ser que, para Tomás, el rasgo definitorio de la essentia estaría constituido por su esencial relación trascendental al esse: la esencia quedaría, entonces, caracterizada, propiamente, como aquello según lo cual se dice que una cosa es (essentia autem est secundum quam res esse dicitur) ${ }^{100}$. Sin embargo, esto no debe entenderse, justamente, en un sentido exclusivamente predicamental, es decir, como si la "relación" de la essentia al "ser" quedara definida por la capacidad de las naturalezas finitas -aquellas que se ordenan bajo géneros y especies-de recibirlo; sino que, al tratarse justamente de una noción "análoga", ésta puede trasladarse incluso a Dios.

En efecto, que la essentia no constituye una noción aplicable con exclusividad a las creaturas, queda evidenciado hacia el final del primer capítulo del De ente, en el que Tomás establece tres tesis fundamentales para nuestro propósito. Primero: dado que el ente (ens) se dice en sentido absoluto y primero de la substancia y, en sentido segundo y relativo de los accidentes, resulta también que la esencia (essentia) está propia y verdaderamente en las substancias y, en cambio, según un cierto modo y relativamente en los accidentes ${ }^{101}$. Segundo: entre las substancias, algunas son simples y otras compuestas, y en unas y en otras hay esencia, mas en las simples la esencia se encuentra de una manera más verdadera y más noble (veriori et nobiliori modo), en tanto que estas substancias también tienen un ser más noble (esse nobilius). Éstas son, pues, causa de las sustancias compuestas, al menos la sustancia primera y simple que es Dios ${ }^{102}$. Tercero: como las esencias de las sustancias simples nos resultan más ocultas, se debe comenzar desde las esencias de las sustancias compuestas, partiendo de lo más fácilio3.

Pues bien, estas afirmaciones de Tomás son importantes por varias razones. Habiendo establecido que la esencia y el ser se encuentran propia y verdaderamente (proprie et vere) en los "entes" que llamamos "substancias",

178101 "Sed quia ens absolute et per prius dicitur de substantiis et per posterius et quasi secundum quid de accidentibus, inde est quod essentia proprie et vere est in substantiis, sed in accidentibus est quodammodo et secundum quid" (ibid., c. 1).

102 "Substantiarum vero quaedam sunt simplices et quaedam compositae, et in utrisque est essentia, sed in simplicibus veriori et nobiliori modo, secundum quod etiam esse nobilius habent. Sunt enim causa eorum quae composita sunt, ad minus substantia prima simplex, quae Deus est" (ibid., c. 1).

103 "Sed quia illarum substantiarum essentiae sunt nobis magis occultae, ideo ab essentiis substantiarum compositarum incipiendum est, ut a facilioribus convenientior fiat disciplina" (ibid., c. 1). 
sostiene además que aquellos se encuentran en un modo más verdadero y noble (veriori et nobiliori modo) en las sustancias simples, especialmente, en la "substancia primera" que es Dios, en virtud de su poder causal vis-à-vis de las substancias compuestas. Estas tesis implican, por lo tanto, atribuirle a Dios las nociones de "ente", "substancia”, “esencia” y "ser”. Ahora bien, ¿significa esta atribución que estas nociones son dichas de Dios y de las creaturas en un sentido univoco y predicamental? La respuesta a esta pregunta se deja ya entrever en las tesis expuestas, y se precisa y completa en el trascurso del opúsculo. La clave está en la anticipada afirmación de que la esencia se encuentra de manera más verdadera y noble en aquellas realidades que también poseen un ser (esse) más noble. Ciertamente, como demostrará el Aquinate en el capítulo tercero del De ente, en la medida en que las cosas tienen el ser no por sí mismas sino como recibido a partir de otro ${ }^{104}$, es necesario que exista una realidad que sea "causa" del ser de todas las cosas: esta realidad no puede ser sino el esse tantum, pues, de lo contrario, se iría al infinito en la serie de causas ${ }^{105}$. De esta manera, mientras las creaturas poseen un ser (esse) realmente distinto de su esencia (essentia), y así limitado y finito ${ }^{106}$, en Dios el ser y la esencia se identifican, y así Dios posee todas las perfecciones ${ }^{107}$.

Ya en estos textos, pues, se advierte no solo un uso "análogo" sino también "trascendental" de los términos ens, essentia y esse. En efecto, si se parte del ens en su acepción categorial, esto es, en cuanto es dividido en los géneros supremos y significa la "esencia" según la cual se dice que una cosa "es", el descubrimiento de la distinción real del esse y la essentia en el

\footnotetext{
104 "Omne autem quod convenit alicui vel est causatum ex principiis naturae suae, sicut risibile in homine, vel advenit ab aliquo principio extrinseco, sicut lumen in aere ex influentia solis. Non autem potest esse quod ipsum esse sit causatum ab ipsa forma vel quiditate rei (dico sicut a causa efficiente) quia sic aliqua res esset sui ipsius causa et aliqua res seipsam in esse produceret, quod est impossibile. Ergo oportet quod omnis talis res, cuius esse est aliud quam natura sua habeat esse ab alio" (ibid., c. 3).

105 "Et quia omne, quod est per aliud, reducitur ad illud quod est per se sicut ad causam primam, oportet quod sit aliqua res, quae sit causa essendi omnibus rebus, eo quod ipsa est esse tantum. Alias iretur in infinitum in causis, cum omnis res, quae non est esse tantum, habeat causam sui esse, ut dictum est" (ibid., c. 3).

${ }^{106}$ En lo que se refiere a las substancias intelectuales creadas: "Secundo modo invenitur essentia in substantiis creatis intellectualibus, in quibus est aliud esse quam essentia earum, quamvis essentia sit sine materia. Unde esse earum non est absolutum, sed receptum et ideo limitatum et finitum ad capacitatem naturae recipientis, sed natura vel quiditas earum est absoluta, non recepta in aliqua materia" (ibid., c. 4). En lo que se refiere a las substancias compuestas de materia y forma: "Tertio modo invenitur essentia in substantiis compositis ex materia et forma, in quibus et esse est receptum et finitum, propter hoc quod ab alio esse habent, et iterum natura vel quiditas earum est recepta in materia signata" (ibid., c. 4).

107 “...ita Deus in ipso esse suo omnes perfectiones habet" (ibid., c.4).
} 


\section{seno de la creatura y de su identidad real en el ser divino ${ }^{108}$, parece permitir situar la noción de "ente" en una dirección trascendental y vertical -y así no predicamental-, gracias a la cual es posible predicarla no solo de la creatura}

108 Cabe destacar, en relación con este tema, que un importante debate se ha generado entre los intérpretes del pensamiento tomasiano en torno al "lugar" que cada una de estas tesis (la distinción real de ser y esencia en las creaturas y la identidad real en el ser divino) ocupa en el proceso argumentativo del De ente. Así, mientras algunos autores sostienen que la tesis de la distinción real es demostrada con anterioridad a la afirmación de la existencia de Dios (Wippel, J. F., “Aquinas's Route to the Real Distinction: A Note on 'De Ente Et Essentia", en: The Thomist: A Speculative Quarterly Review, 43 (1979), pp. 279-295), constituyendo la primera un presupuesto de la segunda, otros sostienen que la demostración de la existencia de Dios, constituye un requisito necesario para la demostración de la distinción real en toda creatura (Owens, J., "Quiddity and Real Distinction in St. Thomas Aquinas", en: Mediaeval Studies, 27 (1965), pp. 1-22). Al no poder reproducir aqui el extenso debate en toda su complejidad, resulta importante para nuestro tema subrayar la tesis de Owens, según la cual la noción de esse como actus essendi (acto y perfección reales) solo es alcanzada en el momento en que se conoce a Dios como el ser mismo o ipsum esse subsistens, por la vía de la causalidad eficiente, que prueba la existencia de una Primera Causa de todas las cosas. En efecto, puesto que esta Primera Causa no puede ser sino el esse tantum (ya que de lo contrario recibiría el ser de otro), recién ahora la inteligencia descubre al esse "en su contenido" como "perfección real", y no como un mero nombre o palabra "vacia" de correlato real (que no vendría en el fondo a significar más que la esencia en cuanto existente). Así pues, solo una vez que se ha descubierto a Dios como el esse tantum, es posible adjudicar a las creaturas un ser (esse) como componente o perfección real en las cosas, distinto de la esencia. Esto implicaría, entonces, que primero Dios es conocido como "ser" y, solo después, el ser es adjudicado a la creatura, de manera que el ser (actus essendi) de la creatura solo es conocido derivadamente, a partir del ser de Dios. Si esto fuera así, las palabras de Marion tendrian mucho de cierto al decir que "...la primacía del esse implica sobre todo, que él deba comprenderse... a partir de Dios, y no que Dios pueda concebirse adecuadamente a partir del esse": de manera que el ser asignado a Dios, exceptuándose del ser común y creado, se exceptúa también entonces "de lo que nosotros comprendemos y conocemos bajo el título de ser" (Marion, Jean-Luc, Dieu sans l'être, 2002, pp. 321-322). Sin embargo, aún si admitiéramos la tesis de Owens, no parece que ese sea, de todas maneras, el sentido de las palabras de Marion. En efecto, mientras que, para Owens, el nombre de ipsum esse le adviene a Dios por la vía metafísica de la causalidad eficiente (según el sentido que hemos expuesto) y luego el esse es adjudicado a las creaturas como el primer efecto creado (ser participado y finito), para Marion, el "ser" cuyo acto Dios realiza debe ser pensado "según determinaciones teológicas", descubriéndose así él mismo ya "fuera del ser" y de la metafisica (ibid., p. 322). A este respecto, Marion elogia las palabras de A. D. Sertillanges, para quien "Dios interviene en la especulación metafisica únicamente en tanto que principio del ser, principio inefable e innombrable" (ibid., p. 327). Así pues, "quien aloje a Dios en el ser y en las categorias del ser lo está negando inconscientemente" (ibid., 327.). Para Marion, Dios es un "esse sin el ser" (ibid., p. 329), "un más allá del ser mismo" (ibid., p. 330) o un "sobre-ser" (ibid., p. 327, Nota: 67). Esto resulta comprensible si se observa que la noción de esse en Marion queda

180 dominada por la acepción "metafisica” (=conceptual) del ser: “...l'excès de l'esse propre à Dieu annule toute acception métaphysique (conceptuelle) de l'être" (ibid., p. 322). Si el "ser" es entendido "conceptualmente", entonces es claro que no puede ser aplicado a Dios. Sin embargo, ¿es este el esse descubierto por Tomás? En este sentido, Marion parece no dar cuenta de la noción propiamente tomasiana del esse como actus essendi, tanto en Dios como en el ente finito, y esto provoca que no sea posible para Marion situar a Dios sino "fuera" del "ser", en ruptura absoluta con el ser de la creatura: “...reprenons l'heureuse formule de Th. D. Humbrecht: 'Dieu ne perd pas sa distance à l'être, c'est au contraire ce qu'il est qui la fonde et la préserve'... ; mais il eût fallu en conclure que si c'est son être qui le maintient à distance de l'être, alors son être n'équivaut tout simplement pas à l'être" (ibid., p. 322). 
sino también de Dios, quien no se deja encerrar en ningún género. Es claro, en este sentido, que en una filosofia como la de Aristóteles, que no admite una distinción real entre la esencia y el ser, sino más bien una esencial identidad real (coherente con su crítica al platonismo) ${ }^{109}$, la ciencia del "ente en cuanto ente" no es sino la ciencia de la "esencia" y, en último término, de la esencia de la "substancia", el analogado principal. Al contrario, en el caso de Tomás, el descubrimiento del esse como "acto" y "perfección" distintos de la esencia en el seno de la creatura, y como el ipsum esse subsistens en la realidad divina, coloca al "ente" en dirección "trascendental", esto es, como haciendo referencia directa e inmediatamente al acto de ser, aunque cosignificando también la esencia. De allí que Tomás se permita concluir en el De ente que la primera causa, que es Dios, es "el ente primero, que es solamente ser (esse tantum)"110. Esta referencia directa e inmediata del ens al actus essendi, como primer acto del ente, quedará luego explicitada y subrayada en otros textos del Aquinate, como en su Comentario a la Metafísica de Aristóteles, donde establece: "hoc vero nomen ens, imponitur ab actu essendi"111.

Sin embargo, cuando Tomás llama a Dios "el ente primero que es solamente ser" (esse tantum o ipsum esse subsistens), ¿qué debe entenderse por esto? ¿un ser absolutamente carente de esencia? Como hemos intentado mostrar, no parece que este sea el caso. Al contrario, en el capítulo cuarto,

\footnotetext{
109 Según comenta Gilson, no se ve cómo sería posible una distinción real entre el ser y la esencia, en una filosofia como la de Aristóteles: “...pour que la critique aristotélicienne du platonisme soit justifiée, il faut que l'essence soit identique à 'ce qui est' [1'ousía]. En effet, si elle ne l'était pas, notre science des essences ne serait pas une science du réel concret. Nous retomberions dans tous les inconvénients qu'offre la doctrine des Idées, puisque la connaissance de la quiddité, ou essence, ne serait plus la connaissance du réel donné dans l'expérience, mais celle d'un monde abstrait, pur produit de notre imagination à l'image du monde sensible. La quiddité se confond donc bien avec l'ousía, c'est-à-dire avec l'être même dont on peut dire qu'il existe comme par définition. Une fois rendus en ce point, il est inutile de vouloir pousser plus avant dans l'analyse de l'être. Non pas seulement inutile, mais absurde. La seule cause qui fasse qu'une chose soit ce qu'elle est, c'est en effet sa forme, quiddité ou essence ; or cette forme, quiddité ou essence, n'est la cause de cet être, que parce qu'elle en est l'ousia et la réalité même. Chercher pourquoi une chose est, c'est chercher pourquoi elle est elle-même, c'est donc vraiment ne rien chercher du tout" (Gilson, Étienne, L'être et l'essence, París: Vrin, 2000, p. 62).

110 "Patet ergo quod intelligentia est forma et esse et quod esse habet a primo ente, quod est esse tantum. Et hoc est causa prima, quae Deus est" (Aquino, Tomás de, De ente et essentia, c. 3). La cursiva es nuestra.

111 “...hoc nomen res imponitur a quidditate tantum; hoc vero nomen ens, imponitur ab actu essendi : et hoc nomen unum, ab ordine vel indivisione... Unde ista tria, res, ens, unum, significant omnino idem, sed secundum diversas rationes" (Aquino, Tomás de, Sententia libri Metaphysicae [=In duodecim libros Metaphysicorum Aristotelis expositio], IV, 2, n 6). Y también: “... et sic imponitur hoc nomen res, quod in hoc differt ab ente, secundum Avicennam in principio Metaphys., quod ens sumitur ab actu essendi, sed nomen rei exprimit quiditatem vel essentiam entis" (Aquino, Tomás de, De veritate, q. 1, art. 1, resp.).
} 
Tomás retoma lo visto precedentemente y sostiene que se encuentra, en las "substancias" 12 , un triple modo de tener "esencia". Pues bien, en relación con el primero, "hay algo que es, como Dios, cuya esencia es su ser mismo, y por eso se encuentran algunos filósofos que dicen que Dios no tiene quididad o esencia, pues su esencia no es otra cosa que su ser"113. Contrariamente a la opinión de Marion, quien interpreta este texto como una aprobación de parte de Tomás de la tesis de la ausencia de esencia en Dios, entendemos que aquí el Aquinate tan solo busca expresar el modo especial en el que la esencia se encuentra en Dios -a saber, como idéntica a su esse-, recogiendo la opinión de "algunos filósofos" y buscando poner al descubierto de dónde una opinión como aquella ha podido nacer. No obstante, el contexto inmediatamente anterior y posterior muestra, a nuestro modo de ver, que el esse tantum corresponde al esse que es idéntico a la essentia. Acerca de éste, afirma Tomás, que no está

${ }^{112}$ En el De ente, Tomás de Aquino llama a Dios "substancia" (primera). Ahora bien, es claro que, para el Aquinate, Dios no puede ser llamado "sustancia" si por esta se entiende la "categoria" de la substancia, según la división predicamental de Aristóteles. Sin embargo, entendido el término "substancia" en un sentido amplio (largo modo), que trasciende las categorías y según el cual se incluye solamente lo que hay de perfección en la substancia (como no inherir en otro o ser por sí mismo, y perfecciones de este tipo), este término puede, según el modo de predicarse los nombres de Dios, decirse efectivamente de Él. Así, la "substancia" es predicada tanto de Dios como de las creaturas, aunque no unívocamente, sino análogamente (constituyendo Dios el analogado principal). Así reza, pues, la respuesta de Tomás a la pregunta de si Dios es una "sustancia" en el sentido categorial en que Aristóteles usaba este término: "Ad primum ergo dicendum, quod Deus simpliciter non est accidens, nec tamen omnino proprie potest dici substantia; tum quia nomen substantiae dicitur a substando, tum quia substantia quidditatem nominat, quae est aliud ab esse ejus. Unde illa est divisio entis creati. Si tamen non fieret in hoc vis, largo modo potest dici substantia, quae tamen intelligitur supra omnem substantiam creatam, quantum ad id quod est perfectionis in substantia, ut non esse in alio et hujusmodi, et tunc est idem in praedicato et in subjecto, sicut in omnibus quae de Deo praedicantur; et ideo non sequitur quod omne quod est substantia, sit Deus; quia nihil aliud ab ipso recipit praedicationem substantiae sic acceptae, secundum quod dicitur de ipso; et ita propter diversum modum praedicandi non dicitur substantia de Deo et creaturis univoce, sed analogice. Et haec potest esse alia ratio quare Deus non est in aliquo genere, quia scilicet nihil de ipso et de aliis univoce praedicatur" (Aquino, Tomás de, Scriptum super Sententiis, lib. 1, d. 8, q. 4, a. 2, ad 1). Sobre este punto, comenta Maritain que el término "substancia", siendo originariamente unívoco, puede, sin embargo, ser objeto de una operación de "trascendentalización", por la cual se vuelve transferible a Dios: "On voit que le mot substance est rendu transférable à Dieu; la notion de substance est rendue transférable à Dieu 182 par une opération spéciale, si je puis dire, de purification et d'extension qui 'transcendantalise' et rend analogue une notion primitivement univoque, puisque primitivement, au sens tout à fait propre, ce mot désigne une catégorie, un genre suprême Il en va de même, par parenthèse, de la notion de relation, qui désigne primitivement et en propre une des catégories, et qui cependant peut être, elle aussi transcendantalisée pour être transférée à Dieu même, où elle s'applique aux personnes divines" (Maritain, Jacques, "Sur la doctrine de l'Aséité divine", 1943, p. 46).

${ }_{113}$ "Aliquid enim est, sicut Deus, cuius essentia est ipsummet suum esse; et ideo inveniuntur aliqui philosophi dicentes quod Deus non habet quiditatem vel essentiam, quia essentia sua non est aliud quam esse eius. Et ex hoc sequitur quod ipse non sit in genere... " (Aquino, Tomás de, De ente et essentia, c. 4). 
en un "género", ya que es necesario que lo que está en un género tenga una quididad (quiditas) además (praeter) de su ser (esse) ${ }^{114}$, esto es, que tenga una quididad "distinta" de su ser"15. Así pues, el ser que es Dios es de tal condición que no se le puede hacer "adición" de ninguna cosa ${ }^{116}$, pues todas las perfecciones y noblezas que están en todos los géneros le convienen a él según su propio ser simple 117 .

Esta interpretación parece ser confirmada por otros textos en los que Tomás claramente atribuye la esencia a Dios: "respondeo dicendum quod Deus est idem quod sua essentia vel natura"118; "respondeo dicendum quod Deus non solum est sua essentia, ut ostensum est, sed etiam suum esse"119. Efectivamente, luego de haber mostrado en Summa theologiae I, q. 3, a. 3 que Dios es la misma deidad (ergo Deus est ipsa deitas), el Aquinate se propone demostrar que en Dios el ser y la esencia son lo mismo (Summa theologiae I, q. 3, a. 4). Para esto, presenta un argumento que nos resulta esclarecedor: alli sostiene que, puesto que el ser es la actualidad de toda forma o naturaleza, la bondad o la humanidad no es significada como actual, sino en la medida en que la significamos como teniendo el ser. De allí que el mismo ser se compare a la esencia en tanto es distinta de él, como el acto a la potencia. Ahora bien, puesto que en Dios nada es potencial, como ya ha sido demostrado, se sigue que en Él la esencia no difiere de su ser, por lo tanto, su esencia es su propio ser ${ }^{120}$.

Pues bien, nos resulta claro a partir de este argumento que, para el Aquinate, aunque en las creaturas el ser se compare a la esencia como el acto a la potencia, la esencia no indica intrínsecamente potencialidad y, por este motivo, puede ser aplicada a Dios. Ciertamente, si el concepto de esencia

\footnotetext{
114 "Et ex hoc sequitur quod ipse non sit in genere, quia omne quod est in genere oportet quod habeat quiditatem praeter esse suum, cum quiditas vel natura generis aut speciei non distinguatur secundum rationem naturae in illis, quorum est genus vel species, sed esse est diversum in diversis" (ibid., c. 4).

115 "Et quia in istis substantiis quiditas non est idem quod esse, ideo sunt ordinabiles in praedicamento, et propter hoc invenitur in eis genus et species et differentia...” (ibid., c. 4).

116 "Hoc enim esse, quod Deus est, huius condicionis est, ut nulla sibi additio fieri possit; unde per ipsam suam puritatem est esse distinctum ab omni esse" (ibid., c. 4).

117 "Similiter etiam, quamvis sit esse tantum, non oportet quod deficiant ei reliquae perfectiones et nobilitates, immo habet omnes perfectiones, quae sunt in omnibus generibus. Propter quod perfectum simpliciter dicitur, ut philosophus et Commentator in V metaphysicae dicunt. Sed habet eas modo excellentiori omnibus rebus, quia in eo unum sunt, sed in aliis diversitatem habent. Et hoc est, quia omnes illae perfections conveniunt sibi secundum esse suum simplex; sicut si aliquis per unam qualitatem posset efficere operationes omnium qualitatum, in illa una qualitate omnes qualitates haberet, ita Deus in ipso esse suo omnes perfectiones habet" (ibid., c. 4).

${ }_{118}$ Aquino, Tomás de, Summa Theologiae, I, q. 3, a. 3.

${ }_{119}$ Ibid., I, q. 3, a. 4.

${ }^{120}$ Ibid., I, q. 3, a. 4.
} 
implicara potencialidad, puesto que Dios es puro acto, ésta debería ser negada de Él. No obstante, vemos que no es así: Tomás no concluye "se sigue que en Dios no hay esencia", sino "se sigue que en Él la esencia no difiere de su ser: su esencia es su propio ser". Podría afirmarse, entonces, que solo en tanto creada la esencia implica una potencialidad, en relación con su acto de ser, del cual difiere. En efecto, tal como afirma Maritain, la essentia es fundamentalmente acto y perfección ${ }^{121}$. De allí que Tomás sostenga, en un conocido texto del $D e$ potencia $^{122}$, que el esse constituye el acto de todos los actos y la perfección de todas las perfecciones; sin embargo, no dice actualitas omnium potentiarum ${ }^{123}$. Así pues, nos parece que la esencia -entendida como "lo que una cosa es"-, no encierra intrínsecamente ni potencialidad ni limitación alguna, sino solo en la medida en que se da en la creatura.

En este sentido, nuevamente debería atenderse aquí a la diferencia establecida por el Aquinate entre res significata y modus significandi: ciertamente, conocemos a Dios a partir de las perfecciones procedentes de Él y que están en las creaturas, aprehendiéndolas tal como se encuentran en ellas. Cuando las aplicamos a Dios, sin embargo, lo hacemos según lo que estas perfecciones significan (res significata), dejando de lado el modo de significarlas (modus significandi), que corresponde propiamente a las creaturas ${ }^{124}$. A nuestro parecer, es este, justamente, el modo de proceder que pone en marcha el Aquinate en su De ente et essentia cuando parte del análisis de la essentia en las sustancias compuestas, para luego remontarse al análisis de la essentia tal como se encuentra en las sustancias simples, y finalmente en la primera causa, Dios. Puesto que las esencias de estas sustancias nos resultan más ocultas, se debe comenzar el aprendizaje a partir de las sustancias compuestas, yendo así de lo más fácil, a lo más dificultoso ${ }^{125}$. Este proceso implica, justamente, el abandono de los modos de significar propios de las creaturas, los cuales expresan modos de ser limitados de las perfecciones. Así, Tomás puede afirmar que Dios posee todas las perfecciones que están en todos los géneros, aunque de modo más excelente (modo excellentiori) que todas las cosas, ya que en Él son uno,

\footnotetext{
121 “...c'est un acte, c'est une perfection, c'est le constitutif intelligible des choses" (Maritain, J., Sur la doctrine de l'Aséité divine, 1934, p. 47).

122 “...Unde patet quod hoc quod dico esse est actualitas omnium actuum, et propter hoc est perfectio omnium perfectionum" (Aquino, Tomás de, De potentia, q. 7, a. 2, ad 9).

${ }^{123}$ Maritain, J., Sur la doctrine de l'Aséité divine, p. 47.

${ }^{124}$ Aquino, Tomás de, Summa theologiae, I, q. 13, a. 3.

125 "Sed quia illarum substantiarum essentiae sunt nobis magis occultae, ideo ab essentiis substantiarum compositarum incipiendum est, ut a facilioribus convenientior fiat disciplina" (Aquino, Tomás de, De ente et essentia, c. 1).
} 
mientras que en las otras cosas tienen diversidad: "et hoc est, quia omnes illae perfectiones conveniunt sibi secundum esse suum simplex"126.

En relación con la manera de predicar ciertas perfecciones de Dios, sostiene J. Maritain que la noción exacta de "analogia" comporta una transfiguración intrínseca (cualitativa, y no cuantitativa) del objeto de intelección, de manera que lo significado por nuestros conceptos (el significatum) permanece, cayendo, sin embargo, el modo de significación. Este modo, que nos es propio, es esencialmente imperfecto y deficiente en lo que se refiere al objeto significado, cuando este objeto significado es Dios, la causa primera ${ }^{127}$. Pues bien, esta deficiencia, esta imperfección radical del modo de significar de nuestros conceptos, afirma el autor, vale tanto para el esse como para la essentia: uno y otro "objetos de noción" (el ser y la esencia) se realizan formal-eminentemente en Dios, aunque "transfigurados" en Él, de un modo que en absoluto nos podemos representar ${ }^{128}$. Así pues, no conocemos el ser divino y la esencia divina según lo que son en sí mismos, sino imperfectamente y por analogía, siendo, entonces, en este sentido, la teología negativa o apofática, superior a la teología afirmativa o catafática ${ }^{129}$. No obstante, podemos afirmar, en relación con estos términos (esse y essentia), lo que ya habiamos sostenido respecto de otros nombres que expresan perfecciones trascendentales, a saber, que estos se aplican a Dios en sentido verdadero y propio (vere et proprio) y, más aún, veriori et nobiliori modo.

Siendo esto así, no parece que adjudicar la essentia a Dios traiga aparejado como consecuencia la necesidad de una comprensión "representativa" del

\footnotetext{
126 “...[Deus] habet omnes perfectiones, quae sunt in omnibus generibus. Propter quod perfectum simpliciter dicitur, ut philosophus et Commentator in V metaphysicae dicunt. Sed habet eas modo excellentiori omnibus rebus, quia in eo unum sunt, sed in aliis diversitatem habent. Et hoc est, quia omnes illae perfectiones conveniunt sibi secundum esse suum simplex" (ibid., c. 4). Y en otro lado: "Divina autem essentia in se nobilitates omnium entium comprehendit, non quidem per modum compositionis, sed per modum perfectionis, ut supra ostensum est" (Aquino, Tomás de, Summa contra Gentiles, I, c. 54, n. 6).

127 "La notion exacte d'analogie comporte... une transfiguration intrinsèque, qualitative, non quantitative, de l'objet d'intellection; en sorte que le signifié de nos concepts, le significatum demeure, mais en Dieu leur mode de signifier tombe, sans que nous sachions comment; le mode de signifier de nos concepts... reste essentiellement imparfait et déficient à l'égard de l'objet signifié, lorsque cet objet signifié est Dieu, la cause première" (Maritain, J., Sur la doctrine de l'Aséité divine, p. 50).

128 "Et cette déficience, cette imperfection radicale du mode de signifier de nos concepts vaut aussi bien pour l'esse, pour l'exister, que pour l'essentia, pour la nature. L'un et l'autre objets de notion, tout en se réalisant formellement en Dieu (formellement-éminemment), sont transfigurés en Dieu... d'une manière que nous ne pouvons absolument pas nous représenter. C'est en ce sens-là que la théologie négative ou apophatique est supérieure à la théologie affirmative ou cataphatique... " (ibid., p. 50).

129 “...et l'existence divine comme l'essence divine, nous les connaissons non pas selon ce qu'elles sont en elles-mêmes, mais imparfaitement et par analogie" (ibid., p. 50).
} 
ser divino, como si su esencia pudiera ser aprehendida en un concepto y definida en términos de género y diferencia específica. No obstante, es el rechazo a esta consecuencia lo que pareciera inducir a Marion a interpretar el texto del $\mathrm{De}$ ente en el sentido de una afirmación de la ausencia de essentia en Dios ${ }^{130}$. En consecuencia, esta "irreductibilidad" del ser a la esencia en Dios, garantizaría, a los ojos del autor, la exclusión del esse divino de la acepción categorial del ser y de su inteligibilidad "representativa", tal como quedan perfiladas en la metafisica aristotélica, pues en el substancialismo esencialista de Aristóteles, el ser de la cosa quedaría identificado con su misma esencia, la cual es objeto de definición. En este sentido, aunque Marion invoca como rasgo distintivo de la filosofia tomasiana la distinción real de esencia y ser en la creatura, no parece que esta tenga real cabida en su argumentación. Efectivamente, para quienes defienden la tesis de la distinción real en la creatura, su aceptación permitiría considerar al ente en una dirección trascendental (que excede al aristotelismo), según la cual la essentia quedaría esencialmente determinada por su relación trascendental al actus essendi, ahora entendido como acto primero del ente y respecto del cual la esencia difiere realmente. Sin embargo, el análisis de Marion, que invoca en repetidas ocasiones la doctrina de la distinción real, nos parece, se limita finalmente a una oposición entre el "ser" en su acepción aristotélica (esto es, como idéntico a la substancia y a la esencia definible) a nivel de los seres finitos, y el "ser puro" (sin esencia) a nivel del ser divino. En definitiva, entendemos que su comprensión del "ser" queda dominada por la acepción aristotélica del ser (y su inteligibilidad representativa), debiendo, en última instancia, expulsar a Dios del ámbito del "ser", por lo que éste se convierte finalmente en "un más allá del ser mismo"131, absolutamente incognoscible.

\footnotetext{
130 "Mais un troisième argument (c) marque définitivement comment l'excès de l'esse propre à Dieu annule toute acception métaphysique (conceptuelle) de l'être. Thomas d'Aquin l'expose soit directement, soit indirectement. -Directement, en identifiant l'essence divine à l'esse...; suivant cette voie, Dieu n'a pas d'autre essence que l'esse, qui en tient lieu, annulant ainsi la composition partout ailleurs réelle de l'esse avec l'essence.- Mais, indirectement le même résultat se formule encore plus radicalement, particulièrement en deux textes.... Sans doute Thomas d'Aquin ne ratifie-t-il pas littéralement la thèse de l'absence d'essence en Dieu; mais le simple fait qu'il motive cette absence par sa propre thèse sur la non-composition en Dieu de l'esse et de l'essence suffit à confirmer son accord avec les 'philosophes"' (Marion, J-L., Dieu sans l'être, 2002, p. 322).

${ }^{131}$ Marion, J-L., Dieu sans l'être, 2002, p. 330. Ver Nota nº 104.
} 


\section{Conclusión}

Tal como lo hemos anticipado al comienzo de nuestro trabajo, nuestro propósito ha sido el de examinar la interpretación de Marion acerca del pensamiento de Tomás de Aquino, particularmente, en lo referido a la posibilidad de alcanzar algún tipo de conocimiento filosófico-natural de la realidad divina. En este sentido, en la lectura que Marion hace de Tomás, el autor no solo afirma que el ser de Dios no puede bajo ningún aspecto ser objeto de representación conceptual, sino que parece, también, abogar por una completa incognoscibilidad del ser divino ${ }^{132}$. En efecto, -sostiene- aunque la existencia de la Causa pueda inferirse a partir de sus efectos por distintas viae, esta conserva un ser/ esencia absolutamente desconocidos y, en este sentido, verdaderamente innombrables $^{133}$. Según nuestro modo de ver, la proposición "Dios es" no indicaría para el autor más que un juicio existencial, a saber, "Dios existe en la realidad" (est aliquid in rerum natura $)^{134}$, por lo que no es posible, en consecuencia, atribuirle a Dios, con sentido, ni la "entidad" ni la "esencia" ni el "ser"135, ni ninguna de las perfecciones absolutas del ente. Ahora bien, tal concepción obligaría, en nuestra opinión, no solo a una predicación equívoca de los términos si estos pretendieran atribuirse simultáneamente a Dios y a las creaturas, sino también a una afirmación de la incapacidad absoluta de la razón humana de tener algún tipo de conocimiento acerca del ser divino ${ }^{136}$. Sostener esta opinión no sería imposible, pero, como hemos intentado mostrar, no parece corresponder,

\footnotetext{
132 "Un dernier argument confirme sans ambigüité l'exception métaphysique de cet esse: (d) son inconnaissabilité. En effet, l'irréductibilité de l'esse à toute essence signifie l'impossibilité de l'articuler prédicativement, donc de le dire discursivement, bref de le comprendre; ainsi ce pur esse se révèle-t-il en principe aussi inconnaissable que le Dieu qu'il désigne.... En tant qu'acte pur d'être sans aucune référence à la composition ordinaire propre à l'étant métaphysique, l'esse divin reste aussi inconnu que Dieu, auquel précisément il revient...” (ibid., p. 324).

133 “...si les effets ne peuvent se comprendre que référés à la cause, la cause, en retour, même si son existence peut s'inférer des effets en autant de viae, n'en garde pas moins une essence absolument inconnue" (ibid., p. 309).

${ }_{134}$ Aquino, Tomás de, Summa contra Gentiles, I, c. 26, n 5.

135 En lo que se refiere a la atribución de la noción de "ser" a Dios, ver: Nota n 104.

${ }^{136}$ En efecto, puesto que Marion parece reducir todo "conocimiento" a la representación conceptual o definición de una esencia, en la medida en que Dios se manifiesta como un esse sin esencia, resulta, entonces, en cuanto tal, incognoscible: "En effet, puisque l'on admet habituellement que l'esse divin reste, pour Thomas d'Aquin, sinon pour son école, sans concept d'être, sans essence, sans définition, sans connaissabilité, bref, un nom négatif, pourquoi prétendre le traiter comme un nom affirmatif, fournissant l'équivalent d'une essence, l'équivalent d'un concept, l'équivalent d'une définition, l'équivalent d'une connaissance?" (Marion, J-L., Dieu sans l'être, 2002, p. 329). La cursiva es nuestra.
} 
independientemente de su éxito o fracaso, a la posición que Tomás de Aquino ha sostenido de forma explícita en sus textos.

Según estos, muchos de los nombres que se predican o atribuyen a Dios expresan perfecciones absolutas que se dan en las creaturas y que preexisten positivamente en Dios según un modo eminente ${ }^{137}$. Si Dios es verdaderamente la causa de todas las cosas, existe entre Dios y las creaturas una cierta semejanza, y es en virtud de esta semejanza que un cierto conocimiento de Dios es posible. ${ }^{138}$ Esto no significa, sin embargo, que la esencia divina sea humanamente aprehensible: tal como Marion argumenta en su trabajo, para el Aquinate, la esencia de Dios permanece incomprensible e inefable en cuanto tal. No obstante, nos parece que un conocimiento imperfecto pero verdadero de Dios es posible, en la medida en que pueden afirmarse o predicarse de Él ciertos atributos. En este sentido, la diferencia establecida por M. Pérez de Laborda entre "incomprensibilidad de la Esencia de Dios" y "cognoscibilidad de Dios" resulta esclarecedora ${ }^{139}$. La distinción entre estos dos modos de conocer correspondería a la diferencia existente entre las dos primeras operaciones del intelecto: la simple abstracción intelectual y el juicio. En efecto, aunque es cierto que la esencia de Dios permanece absolutamente desconocida para el hombre -incluso al final de su esfuerzo por conocerlo de manera filosófica-, esta tesis tiene validez en el ámbito de la primera operación intelectual, a saber, la abstracción, dado que se refiere a "la imposibilidad de formar un concepto adecuado de Dios"140. Ahora bien, la conceptualización no constituye el único modo de conocer para el hombre, ya que "el juicio es también un acto cognoscitivo, por medio del cual

\footnotetext{
137 “...Et sic, quidquid dicitur de Deo et creaturis, dicitur secundum quod est aliquis ordo creaturae ad Deum, ut ad principium et causam, in qua praeexistunt excellenter omnes rerum perfectiones. Et iste modus communitatis medius est inter puram aequivocationem et simplicem univocationem. Neque enim in his quae analogice dicuntur, est una ratio, sicut est in univocis; nec totaliter diversa, sicut in aequivocis; sed nomen quod sic multipliciter dicitur, significat diversas proportiones ad aliquid unum... " (Aquino, Tomás de, Summa Theologiae, I, q. 13, a. 5).

138 "Ad primum ergo dicendum quod, licet in praedicationibus oporteat aequivoca ad univoca reduci, tamen in actionibus agens non univocum ex necessitate praecedit agens univocum. Agens enim non univocum est causa universalis totius speciei, ut sol est causa generationis omnium hominum. Agens vero univocum non est causa agens universalis totius speciei (alioquin esset causa sui ipsius, cum sub specie contineatur), sed est causa particularis respectu huius individui, quod in participatione speciei constituit. Causa igitur universalis totius speciei non est agens univocum. Causa autem universalis est prior particulari. Hoc autem agens universale, licet non sit univocum, non tamen est omnino aequivocum, quia sic non faceret sibi simile; sed potest dici agens analogicum, sicut in praedicationibus omnia univoca reducuntur ad unum primum, non univocum, sed analogicum, quod est ens" (ibid., I, q. 13, a. 5, ad 1).

139 Pérez de Laborda, M., Dios a la vista: el conocimiento natural de lo divino, Madrid: Rialp, 2015, p. 168 .

${ }^{140}$ Ibid., p. 168.
} 
se alcanzan nuevos conocimientos": por este motivo, "que Dios esté más allá de toda conceptualización no significa que no se pueda conocer o que no se pueda hablar de Él con verdad"141. Así, la "incomprensibilidad de la Esencia de Dios" y la "cognoscibilidad de Dios" no resultan tesis incompatibles ${ }^{142}$.

Para terminar, y en razón de estos análisis, consideramos que, aunque Marion destaca acertadamente la tesis tomasiana de la imposibilidad de un conocimiento "representativo" (conceptual) de la esencia divina, no parece admitir la afirmación por parte de Tomás -a nuestros ojos también contundente- de la posibilidad de un conocimiento verdadero mas no exhaustivo del ser divino, a partir de la atribución (a nivel del juicio) de ciertas perfecciones que encontramos en las creaturas y que, predicadas de Dios, significan a Dios mismo, en el sentido que hemos especificado. Creemos que la inclusión de esta última tesis es necesaria para una presentación de la doctrina de Tomás del todo ajustada a sus textos y a su pensamiento. Por otra parte, y en función de los análisis efectuados en torno a la noción de "esencia", tampoco creemos que la tesis de la negación de la existencia de la essentia en Dios constituya un requisito necesario para librar a la concepción tomasiana de la onto-teo-logía y que, a su vez, esta tesis se desprenda efectivamente de los textos del Aquinate. En este sentido, cabe preguntarse si, en el caso de que la doctrina tomasiana no se deje encerrar en la constitución onto-teo-lógica de la metafísica, en el sentido en que Heidegger la postula, ello se deba completa y verdaderamente al conjunto de razones aducidas por el autor.

Recibido: $17 / 10 / 2017$

Aceptado: 09/09/2018

\section{Bibliografia}

Aquino, T., Corpus Thomisticum, Enrique Alarcón (dir.), Navarra: Universidad de Navarra, 2000-: http://www.corpusthomisticum.org/iopera.html.

Aristóteles, Aristotle's Metaphysics, Ross, W.D. (ed.), Oxford: Clarendon Press, 1924. Avicenna, Liber de philosophia prima sive scientia divina, Van Riet, S. (ed.) 2 vol., Lovaina - Leiden: E. Peeters - E.J. Brill, 1977-1980.

\footnotetext{
${ }^{141}$ Ibid., p. 168.

142 "Ad tertium dicendum quod essentiam Dei in hac vita cognoscere non possumus secundum quod in se est, sed cognoscimus eam secundum quod repraesentatur in perfectionibus creaturarum. Et sic nomina a nobis imposita eam significant" (Aquino, Tomás de, Summa Theologiae, I, q. 13, a. 2, ad 3).
} 
Berti, E., Estructura y significado de la 'Metafisica' de Aristóteles, Buenos Aires: Oinos, 2011.

Castello, J., "La predicación de los atributos divinos en Tomás de Aquino", en: Analytica, XIV, 2 (2010), pp. 89-107.

Castello, J., "Dios y el objeto de la metafísica: Tomás de Aquino y el Avicena latino", en: Peretó Rivas, R. (ed.), Temas de Metafísica en la Edad Media, Mendoza: Cuadernos medievales de Cuyo 5, CEFIM - SS\&CC, 2011, pp. 25-42.

Forment, E., Filosofía del ser. Introducción, comentario, texto y traducción del 'De ente et essentia' de Santo Tomás, Barcelona: PPU, 1988.

Gilson, E., L'être et l'essence, París: Vrin, 2000.

Marion, J., Dieu sans l'être, 2ème édition, París: PUF, 2002.

Maritain, J., "Sur la doctrine de l'Aséité divine", en: Mediaeval studies, V, (1943), pp. 39-50. https://doi.org/10.1484/J.MS.2.306543

Pérez de Laborda, M., Dios a la vista: el conocimiento natural de lo divino, Madrid: Rialp, 2015 . 